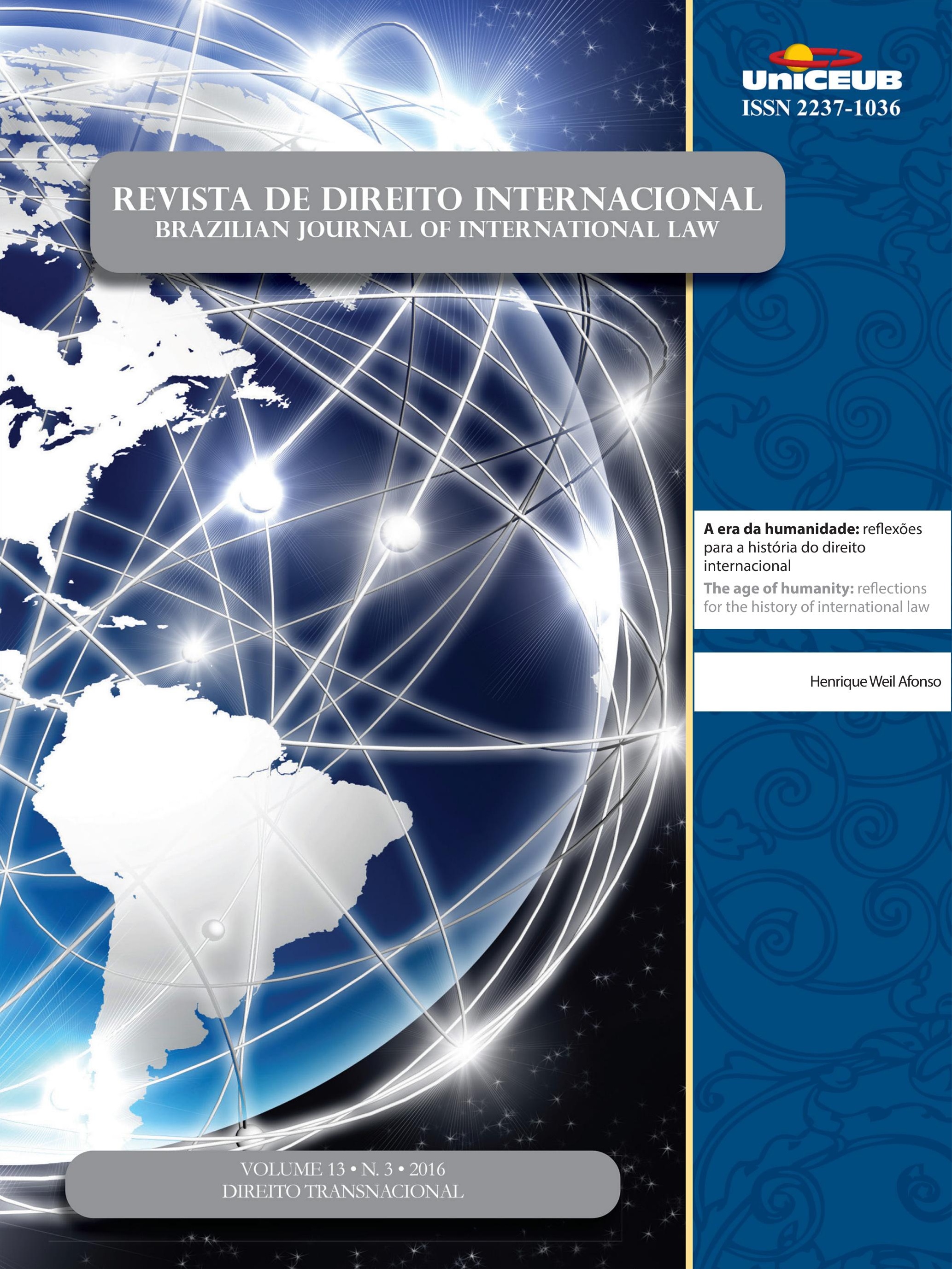


Crônicas da ATUALIdAde do direito internacional .................................................. 2

I. Dossiê Temático: Direito Transnacional .........................................................15

EDITORIAL: O Direito Transnacional - Circulação de normas e relações jurídicas transnacionais .......16 Priscila Pereira de Andrade

A emergênCia do direito transnacional ambiental .............................................18 Priscila Pereira de Andrade

Desafíos y RESPUESTAS TRANSNACIONALES FRENTE A LOS CRÍMENES AMBIENTALES ...............30 Rosmerlin Estupiñan-Silva

DiREITO TRANSNACIONAL E MUdANÇAS CLIMÁTICAS .50 Géraud de Lassus Saint-Geniès

Especies en movimiento: la Convención sobre el Comercio Internacional de Especies Amenazadas de Fauna y Flora Silvestres como espacio de “Encuentro” de discursos, ACTORES Y ESTRATEGIAS EN EL DERECHO AMBIENTAL TRASNACIONAL

María Valeria Berros e Dabel Leandro Franco

El carácter transnacional del Sistema comunitario de ECogestion « Eco-ManageMENT AND Audit SCHEME » (EMAS) DENTRo de LA UE y MÁs ALlÁ DE SUS Fronteras ......72 Adélie Pomade

O CONCEITO DE CONDUTA EMPRESARIAL RESPONSÁVEL À LUZ DOS ORDENAMENTOS JURÍDICOS BRASILEIRO, INTERNACIONAL E TRANSNACIONAL

Gabriel Webber Ziero

ARBITRAGEM NO DIREITO TRIBUTÁRIO INTERNACIONAL E NO DIREITO INTERNACIONAL DOS INVESTIMENTOS: UMA MANIFESTAÇÃO DO DIREITO TRANSNACIONAL

Vivian Daniele Rocha Gabriel 
O DIREITO TRIBUTÁRIO SOB UMA PERSPECTIVA TRANSNACIONAL

Franciele de Simas Estrela Borges

As Características do Direito Transnacional como Metodologia: Análise sob o enfoQue dos Aspectos Processuais da Arbitragem 126

Flávia Foz Mange

O DIREITO TRANSNACIONAL (“GLOBAL LAW") E A CRISE DE PARADIGMA DO ESTADO-CENTRISMO: É POSSÍVEL CONCEBER UMA ORDEM JURÍDICA TRANSNACIONAL? ...................................... 146

Luiza Nogueira Barbosa e Valesca Raizer Borges Moschen

TransPorte AÉREO E DIREITO TRANSNACIONAL: DA CONVERGÊNCIA À UNIFORMIDADE 160 Mickael R. Viglino

Outros Artigos. 175

O Fundo Monetário Internacional e a proteção dos direitos humanos: uma análise DO PROGRAMA DE CRESCIMENTO E REDUÇÃO DA POBREZA NO HAITI 177

Pablo Henrique Hubner de Lanna Costa e Carlos Alberto Simões de Tomaz

Um estranho no ninho? Padrões privados no Acordo de Barreiras Técnicas ao CoMÉRCIO DA OMC 192

Michelle Ratton Sanchez Badin e Marina Yoshimi Takitani

Os benefícios tributários do programa Inovar-Auto e os princípios da Nação Mais Favorecida e do Tratamento Nacional: uma análise dos argumentos dos Painéis atualmente em Curso contra o Brasil no Órgão de SoluÇão de Controvérsias da OMC . 211 Eric Moraes Castro e Silva

A ERA DA HUMANIDADE: REFLEXões PARA A HISTÓRIA DO DIREITO INTERNACIONAL 236 Henrique Weil Afonso

Precedentes vinculantes nos Estados Unidos da América e no direito brasileiro: Um ESTUDO COMPARADO 264

Patrícia Perrone Campos Mello 
IL DIRITTO AMBIENTALE SECONDO L'OTTICA DEL DIRITTO COSTITUZIONALE POSITIVO E LA RESPONSABILITÀ PER DANNI ALL'AMBIENTE NEL DIRITTO COMUNITARIO: LO STATO DELL'ARTE DEL DIRITTO AMBIENTALE COSTITUZIONALE E COMUNITARIO 287

Elcio Nacur Rezende

DA DESCONSIDERAÇÃo DA PERSONALIDADE JURÍDICA NAS RELAÇÕES CONSUMEIRISTAS BRASILEIRAS: ANÁLISE À LUZ DAS TEORIAS CLÁSSICAS

Daniel Amin Ferraz e Marcus Vinicius Silveira de Sá

ANALYSIS OF ADVANTAGES AND DISADVANTAGES OF FORUMS PRESCRIBED UNDER THE UNCLOS AND STATE PRACTICE: THE WAY AHEAD FOR INDIA ......................................................319

Vinai Kumar Singh

Do governo POR LEIS À governanÇA POR NúMERos: breve anÁlise do Trade in SERVICE AgreEMENT (TISA) ...............................................................................338 Jânia Maria Lopes Saldanha, Rafaela da Cruz Mello e Têmis Limberger

As DIRETIVAS EUROPEIAS COMO NORMA REGULADORA DO DIREITO ADMINISTRATIVO GLOBAL ..356 Alice Rocha da Silva e Ruth Maria Pereira dos Santos

O desenVolvimento da POlítica AGRícola COMUM dA UNião EUROPEIA 375 Tatiana de A. F. R. Cardoso Squeff

A imunidade de Jurisdição das organizaÇões internacionais FaCE AO Direito de aCESSO À JUSTIÇA 391

Fernanda Araújo Kallás e Caetano

O DIREITO INTERNACIONAL ENTRE O DEVER ÉTICO E A AÇÃo POLÍ́TICA: OS FUNDAMENTOS DE UM DEVER DE COOPERAÇÃO INTERNACIONAL NA FILOSOFIA POLÍTICA DE IMMANUEL KANT .405 Ademar Junior Pozzatti

EXTENSÃo E FRAGMENTAÇÃo NO CONTEXTO DA JURISDIÇÃO PENAL INTERNACIONAL .423 Marcus Vinícius Xavier de Oliveira

A DEFINiÇÃo JURÍdiCA DA "COMUNIDADE" .444 Nitish Monebhurrun, Michelle Lucas Cardoso Balbino, Fernanda Castelo Branco Araujo, Othon Pantoja, Míara Bogo Bruno e Cândida Dettenborn Nóbrega 
Comparative Study on Chinese Local Legislation of Science and Technology ProGRESS

LI Xiaoming e LI Yihan

O CONTROLE PENAL DO TRÁFICO DE PESSOAS: CONSTRUÇÃO JURÍDICA, INTERAÇÕES ORGANIZACIONAIS E COOPERAÇÃO INTERNACIONAL

Bruno Amaral Machado e Priscilla Brito Silva Vieira

Desativismo judicial: a extradição Battisti no Supremo Tribunal Federal .505 Francisco Rezek e Israel Paulino

A decisão norte-americana do Caso Myriad: novos paradigmas para a Proteção patenTÁRIA DO CÓDIGO GENÉTICO HUMANO E BIOTECNOLOGIA 514 José Carlos Vaz e Dias e Clarisse De La Cerda 


\section{A era da humanidade: reflexões para a história do direito internacional*}

\section{The age of humanity: reflections for the history of international law}

Henrique Weil Afonso **

\section{Resumo}

O objetivo deste trabalho é analisar controvérsias acerca da hipótese do colapso climático por causas antropogênicas mediante o auxílio de abordagens críticas da história do Direito Internacional. Para sua concretização, optou-se pelo estudo descritivo e analítico, por meio de pesquisa bibliográfica e documental. Nos últimos anos, o possível ingresso da humanidade em uma nova era geológica designada de Antropoceno recebe considerável atenção por parte de historiadores. A ideia segundo a qual, a partir da Revolução Industrial, a humanidade age em uma escala equivalente a uma força telúrica, vem repercutindo na seara historiográfica e torna-se uma temática de apelo global. Em primeiro lugar, porque o Antropoceno suscita problemas referentes à formação histórica da sociedade internacional. Empregando um viés anacrônico, o debate metodológico despertado pela literatura pós-colonial defende a pertinência de temas como colonialismo e imperialismo para a compreensão da agenda internacional do presente. Por essa razão, revela-se frutífera ferramenta analítica para a compreensão das formações discursivas do Antropoceno. Em segundo lugar, os efeitos estimados da atividade antropogênica têm o potencial de desestabilizar as condições de construção do saber histórico sobre os quais a teoria do Direito Internacional encontra sustentação, aspecto este que será problematizado à luz das limitações das intepretações contextualistas da história. Finalmente, o ideal de progresso que confere sentido a variadas formações históricas influentes no Direito Internacional poderá ser revisitado a partir da premissa segundo a qual, no Antropoceno, a teleologia histórica necessita coexistir com horizontes de expectativas menos favoráveis à realização das promessas da modernidade.

Palavras-chave: História do Direito Internacional. Anacronismo. Colapso climático. Antropoceno.

* Recebido em 30/08/2016 Aprovado em 22/10/2016

** Professor Permanente do Programa de Pós-graduação em Direito da Faculdade Damas da Instrução Cristã. Bacharel em Direito pela UFJF. Mestre e Doutor em Direito pela PUC Minas. Atuou como Bolsista PNPD no Programa de Pós-gradução em Direito Agroambiental da UFMT no período 2014-2015. Contato: henriqueweil@hotmail.com

\section{Abstract}

The aim of this article is to analyse certain controversies that concerns climate collapse within a framework of critique influenced by recent methodological debates on the history of International Law. To accomplish the present research, the emphasis has been descriptive and analytical study mainly of literature and selected documents. In recent years, the probable beginning of a new geological era known as the Anthropocene has been re- 
ceiving considerable attention from historians. The assumption that humanity's activities since the Industrial Revolution is equivalent to a telluric force ultimately resonates in historiographical theory and acquires a global appeal. First, it is argued that the Anthropocene holds troubling connections with the formation of international society. Through an anachronic lens, post-colonial literature's input on the history of International Law attracts attention as colonialism and imperialism rise as a problematic dimension of present concerns of international legal thought and institutions' agenda; in this sense, it is worth making use of these analytical tools to widen the understanding of discursive formations related with the Anthropocene. Second, the article draws upon the estimated that anthropogenic-related climate collapse may destabilize the conditions of the construction of historical knowledge over which international legal thought has been based. These aspects will be accessed by means of contextualist interpretations of history. Lastly, the article contemplates an estimation of the viability of progressive teleology of history and makes a case for the validity of expanding the horizons of expectations in order to account for less optimistic readings of the future of international modern society.

Keywords: History of International Law. Anachronism. Climate collapse. Anthropocene.

\section{INTRODUÇão}

"Realmente não existe impedimento físico algum para nos movermos dentro do cosmos. Portanto, eventualmente, isso irá acontecer, porque nós vamos continuar tentando. É uma urgência evolucionária, um imperativo biológico, algo como a própria reprodução", segue a ponderação do moderador do debate dirigida ao convidado Badim, sobrevivente da nave espacial Aurora que retornara à Terra em 2.908 após uma missão de colonização interestelar. Badim, ao lado do amigo Aram e da filha Freya, expressara sua resoluta descrença na viabilidade do projeto de exploração espacial que intentava encontrar um planeta equivalente à Terra. "Existem muitos seres inteligentes aí fora, sem dúvidas, mas eles não podem deixar seus planetas mais do que nós podemos, porque a vida é uma expressão planetária, e só pode sobreviver em seu planeta natal', contestara Badim. ${ }^{1}$
A ficção científica Aurora, de Kim Stanley Robinson, narra a saga épica de um grupo de pessoas em curso pelo espaço sideral a bordo da aeronave Aurora. Seu propósito: estabelecer uma colônia humana na estrela homônima, situada no sistema Tau Ceti, a uma distância de 11,9 anos-luz da Terra. Quando a viagem tem início (século XXVI), a humanidade já havia explorado os demais planetas do Sistema Solar, mas, conforme a fala do moderador, nada deveria impedir que a espécie humana alçasse voos mais distantes. Para ele, certa teleologia histórica estaria por motivar a expansão progressiva pelo Cosmos, enriquecendo a existência até então planetária da vida humana. Já para Badim, Aram e Freya, protagonistas da jornada que rumava à Aurora, a humanidade jamais encontrará outra casa que não a Terra: porque o tênue equilíbrio necessário para que a vida floresça é um evento precioso, de resolvida irrepetibilidade; a vida humana só é humana na Terra.

O enredo fornece pouquíssimas pistas acerca da vida na Terra neste futuro distante, mas imaginável. Em um dos únicos parágrafos dedicados à explicitação da situação terrestre, faz-se menção a um debate contemporâneo que muito recentemente começou a orbitar certos aspectos da teoria e da prática do Direito Internacional: a mudança climática. Na obra de Robinson, fala-se da mudança climática quando da ocasião da descrição de um novo trabalho característico do século XXX. A reconstrução das praias seria a atividade por meio da qual os sobreviventes de Aurora poderiam restabelecer a conexão com a Terra que apenas imaginavam conhecer. Sendo o conteúdo do trecho o seguinte:

Mas é claro que não existem praias. O nível do mar
aumentou vinte e quatro metros entre os séculos
vinte dois e vinte três da era comum por causa de
processos que eles começaram no século vinte e
um e que eles não puderam mais tarde reverter; e,
neste aumento, todas as praias da Terra afogaram.
Nada que eles fizeram para resfriar o clima terrestre
foi suficiente para baixar o nível do mar; isso
levará mais alguns milhares de anos. Sim, eles estão
terraformando a Terra agora. Não há como evitar,
haja vista o dano já foi causado. Nesta era comum
de 2910 , eles estão chamando isto um projeto de
cinco mil anos. Alguns dizem que levará mais. Será
uma corrida com os Marcianos, eles brincam. Mas
por agora é um adeus às praias. Um mundo e um
modo de vida inteiros desapareceram nestes lugares
de que se conta em fábulas, um modo de vida que
remonta ao início da espécie no sul e leste da África,
onde os primeiros humanos frequentemente viviam
envolvidos com o mar. Aquele modo de vida úmido,

429. (Grifo nosso) 
arenoso, ondular, salgado, tocado pelo mar: tudo se foi, junto com muito mais, é claro; animais, plantas, peixes. É parte do evento de extinção em massa que eles ainda lutam para que termine, para escapar. Tanto foi perdido que nunca mais retornará. ${ }^{2}$

O imaginado século XXX de Kim S. Robinson, nos termos das explicações, guardava problemáticas conexões com o presente século XXI. A despeito de a ciência ter tornado possível a viagem interestelar, esta foi incapaz de reverter os processos de mudança climática em definitivo curso no longínquo século XXI. Então, na futura Terra, a atividade de reconstrução das praias oportunizou a reinserção dos tripulantes humanos extraterrestres de Aurora. Em um trágico cenário para uma humanidade que viaja distâncias inconcebíveis para a tecnologia do século XXI e que coloniza corpos celestes - terraformando-os, ou dotando-os das condições necessárias para hospedar a vida humana, como os marcianos do trecho -, a sustentação da vida humana terrestre é constantemente inviabilizada pelos eventos do passado.

Tomando-se como inspiração essa fictícia conexão entre o passado e o futuro da humanidade, alguns dos elementos da passagem acima podem ser realçados a fim de justificar uma aproximação da história do direito com os debates correntes a respeito da mudança climática. Assim, as menções à elevação do nível do mar, à destruição da vida presente nos ecossistemas marinhos, à responsabilidade da humanidade no século XXI e as dificuldades - ou impossibilidade - de reversão do quadro climático integram o contexto temporal de um determinado futuro interespacial que guarda atrelamentos com o passado - ou, o nosso presente. Gaia faz-se, novamente, presente para a sociedade internacional.

Mais especificamente, e com apoio no historiador Reinhart Koselleck ${ }^{3}$, o futuro passado imaginado de Robinson tem início no tempo presente da sociedade internacional, seus modos de vida, sua atividade econômica e, para os fins deste estudo e pela dimensão da questão em foco, a disciplina e prática do Direito Internacional. O espaço de experiências da sociedade internacional do século XXI encena a confecção dos horizontes de expectativas sobre o percurso futuro, este apenas imaginado por Robinson, entretanto conectado às nossas percepções tanto do passado quanto do futuro.

2 ROBINSON, Kim Stanley. Aurora. Orbit: Londres. p. 436. (Tradução nossa).

3 KOSELLECK, Reinhart. Futuro passado: contribuição à semântica dos tempos modernos. Rio de Janeiro: Contraponto, 2012.
Não é sem razão que o quadro de mudanças climáticas que vem se desenhando em pesquisas científicas de instituições como o IPCC ${ }^{4}$ levanta problemas de variadas matrizes. Ultrapassando a rígida demarcação científica que tradicionalmente aloca às Ciências Naturais o estudo de temas como este, nas últimas duas décadas, as Ciências Sociais em geral e, de forma mais específica, a História, a Antropologia e a Filosofia, veem refletindo sobre questões de grande apelo para a sociedade internacional.

Para o Direito Internacional, é no fértil campo da História do Direito onde se depreendem alguns dos esforços de ampliação da compreensão da complexidade de relações do passado, da controvérsia crescente em torno da persistência de processos coloniais e imperiais e, não em desfecho, mas em apertada apresentação do amplo mosaico da ambiência histórica, as idealizações do futuro da sociedade internacional.

Em um ambiente de encantamento com a história da disciplina, no qual tanto os métodos quanto a práxis institucional estão contemplados, a complexidade da mudança climática pode proporcionar a desestabilização da solidez do passado, a problematização do contexto corrente de compreensão do problema e, não menos importante, a atenção para o tipo de horizonte futuro demarcado pela teoria e pelas instituições.

É nesta tríplice convergência que este estudo pretende inquirir sobre a dimensão histórica das mudanças climáticas no âmbito do Direito Internacional. Tome-se nota de que tanto a extensão quanto a complexidade da temática histórica desautorizam - e inviabilizam - estudos de pretensões genéricas. É necessária, neste mote, a composição de um recorte metodológico e a adoção de ferramentas teóricas apropriadas à complexidade em tela, uma vez que a profusão de interpretações referentes à mudança climática parece produzir certa resistência às tentativas de categorização que a própria designação mudança climática propriamente alude.

Este trabalho adotará a designação colapso climático no interesse de destacar as repercussões historiográficas de contextos históricos caracterizados pela incerteza e imprevisibilidade. Nestes termos, o problema enfrentado pode ser explicitado da seguinte maneira: por quais vias a história do Direito Internacional pode ser problematizada

4 Painel Intergovernamental para Mudanças Climáticas, uma coletividade de cientista vinculada à ONU e que desde a década de 1990 realiza estudos periódicos sobre variados aspectos do tema. 
criticamente a partir da ascensão da complexa temática - provisoriamente - designada por colapso climático antropogênico?

Espera-se investigar o referido problema a partir de três eixos analíticos interconectados. Primeiramente, dar-se-á ênfase à recepção do colapso climático nas disciplinas sociais, como a Antropologia, a História e o Direito. A polêmica de que a extensão do impacto da atividade antropogênica no ambiente global teria originado uma nova era geológica na história planetária - o Antropoceno que sucederia o Holoceno - faz sua chegada ao universo jurídico. Todavia, no que possivelmente encapsulam algumas das mais ricas contribuições para a interdisciplinar história do Direito, certas abordagens críticas que se pretendem atentas, por um lado, às hierarquias construídas historicamente e, por outro lado, à instabilidade da dicotomia história natural/ história humana, insistem na problemática do registro histórico e nas instáveis relações entre passado, presente e futuro despertadas pelo Antropoceno.

O segundo eixo compreende a delimitação da metodologia histórica jusinternacionalista. Ver-se-á, por meio do registro do Antropoceno, que a questão climática faculta o acesso ao passado da disciplina em um viés anacrônico e outro diacrônico. Aquele ladeia a crítica pós-colonial quando denuncia narrativas de exploração e de subalternização, e o faz por meio da rejeição do universalismo historicista em favor de uma pluralidade de histórias do Direito Internacional. Já este, em virtude da proximidade com o contextualismo da Escola de Cambridge ${ }^{5}$, investe no balizamento histórico como estratégia para descreditar interpretações históricas estranhas à linguagem, ideologias e valores peculiares a um dado momento e contexto específicos.

Finalmente, o Antropoceno, assim pode suceder, pode representar o tipo de acontecimento apto a desestabilizar ou romper contextos históricos. Adicionalmente, conecta-se com o passado da disciplina e projeta-se nos horizontes de seu futuro. A depender dos marcos temporais adotadas, leituras históricas diversas poderão suscitar profundas reformulações nos problemas juridicamente considerados. Contudo, se o fantasioso mundo de Robinson no Século XXX toma forma em pleno Antropoceno - em que seus protagonistas experimentam condições físicas radicalmente diversas das atuais -, e se o futuro então vivido, mesmo que numa distância

5 SKINNER, Quentin. Meaning and understanding in the history of ideas. History and Theory, Middletown, v. 8, n. 1, p. 3-53, 1969. temporal de aproximadamente um milênio, desdobra-se tal qual os modelos de mudança climática projetados em nosso tempo, então caberia refletir sobre a ideia de futuro da sociedade internacional.

\section{O ANTROPOCENO: A ERA DA HUMANIDADE E A DESESTABILIZAÇÃO DO CONHECIMENTO HISTÓRICO}

Em uma recente coletânea de artigos que discutem variados aspectos do impacto do Antropoceno nas humanidades, os editores Clive Hamilton, Christophe Bonneuil e François Germenne advertem para as dificuldades teóricas que começam a tocar áreas do conhecimento estranhas às Ciências Naturais. "O advento do Antropoceno", escrevem os editores,

Desafia algumas barreiras estabelecidas entre
natureza e cultura, entre clima e política, entre
ciências naturais e ciências sociais e humanidades. O
ponto aqui é mais profundo que uma chamada pela
interdisciplinaridade em torno de objetos 'sócio-
ecológicos' híbridos. A concepção de que o mundo
natural onde sociologia, ciência política, história,
direito, economia e filosofia descansaram por dois
séculos - aquela [concepção] de que uma pronta
reserva inerte de recursos, um impassível pano de
fundo externo do drama das atividades humanas
- é crescentemente difícil de defender. E em uma
época em que 'Gaia' foi acordada novamente, as
concepções exclusivamente sociais de autonomia,
agência, liberdade e reflexividade, que foram os
pilares da modernidade desde o século XIX, estão
tremendo.

A referência feita ao 'advento do Antropoceno' nas ciências humanas foi antecedida por um relativamente breve período de maturação nas Ciências Naturais. De fato, a repercussão da teoria do Antropoceno esteve, em um primeiro momento, restrita ao universo da Geologia e das ciências naturais. No ano 2000, ganha repercussão no meio científico a formulação de Paul Crutzen e Eugene Stoermer a respeito da provável entrada da humanidade em uma nova era geológica que viria a suceder a atual era do Holoceno. Empreendendo um detalhado exame da escala e alcance da atividade humana no planeta desde o marco da Revolução Industrial (meados do século XVIII), o referido autor concluiu que, diante

6 HAMILTON, Clive; BONNEUIL, Christophe; GEMENNE, François. Thinking the anthropocene. In: HAMILTON, Clive; BONNEUIL, Christophe; GEMENNE, François (Eds.). The anthropocene and the global environmental crisis: rethinking modernity in a new epoch. New York: Routledge, 2015. p. 5. (tradução nossa). 
das evidências das ações antropogênicas - aqui simbolicamente representada pelo aumento sem precedentes na emissão de gases de efeito estufa nos últimos dois séculos e meio ${ }^{7}$-, seria mais apropriado "[...] enfatizar o papel central da humanidade na geologia e ecologia propondo o uso do termo 'antropoceno' para a corrente época geológica."»

O Antropoceno consistiria, neste apanhado inicial, no reconhecimento de que a humanidade compõe uma força geológica - uma força telúrica, equivalente, por exemplo, ao deslocamento de placas tectônicas ou maciças erupções vulcânicas - cujos impactos serão sentidos não somente no curto prazo, mas sim por milênios por vir.

A demarcação da gênese desta era geológica - tema este cuja controvérsia repercute ao longo deste trabalho - aponta para a Revolução Industrial em meados do século XVIII, momento marcante na história da humanidade na medida em que representa o começo do uso em larga escala de combustíveis fósseis para a geração da energia requisitada pela expansão da atividade antropogênica. ${ }^{9}$ Evento simbólico, a criação da máquina a vapor

7 Crutzen et al utilizaram os seguintes referenciais: "Nós utilizamos o dióxido de carbono atmosférico como um único, simples indicador para rastrear a progressão do antropoceno. De um valor pré-industrial de $270-285 \mathrm{ppm}$, o dióxido de carbono atmosférico cresceu para cerca de 310 ppm na década de 1950. Desde então a humanidade vem experimentando uma notável explosão, a Grande Aceleração, com consequências significativas para o funcionamento do Sistema Terra. A concentração de CO2 atmosférico aumentou de 310 para 380 ppm desde 1950, com cerca de metade do aumento total desde a era pré-industrial ocorrendo em apenas nos últimos 30 anos." (CRUTZEN, Paul; STEFFEN, Will; MCNEILL, John. The anthropocene: are humans now overwhelming the great forces of nature? Ambio, Estocolmo, v. 36, n. 8, p. 614-621, 2007. p. 614.) (tradução nossa).

8 CRUTZEN, Paul; STOERMER, Eugene. The "anthropocene". Global Change Newsletter, n. 41, p. 17-18, 2000. p. 17. (Tradução nossa)

9 A associação entre o diagnóstico do Antropoceno e as discussões globais sobre a mudança climática veio a pautar estudos posteriores. Nestes, são evidentes tanto elaborações nas proposições seminais quanto delineamentos das propostas de mitigação dos efeitos climáticos deletérios característicos desta nova era geológica. Desse modo, Crutzen e colaboradores procederam à identificação de três possíveis estágios do Antropoceno. Segue, assim, que o primeiro estágio situa-se entre o final do século XIX e meados do século XX, e foi caracterizado por enorme expansão no uso de combustíveis fósseis como carvão, gás natural e petróleo como desdobramentos das modificações científicas introduzidas na Revolução Industrial. Nesse estágio, observa-se substancial incremento atmosférico de óxido nitroso e dióxido de carbono. Inscrito no período 1945-2015, o segundo estágio é marcado, de um lado, pelo aumento da população humana (que mais que dobrou) e, por outro lado, por uma constatação que não encontra precedentes na história registrada: as em 1784 por James Watts inauguraria uma nova etapa da relação entre a humanidade e a natureza. ${ }^{10}$

Consoante o mais recente relatório do Intergovernmental Panel on Climate Change (IPCC), o final de nosso presente século XXI testemunhará um incremento entre 1,1 e 6,4 graus Celsius na temperatura média global. ${ }^{11} \mathrm{O}$ documento dispõe que a "influência humana no sistema climático é clara, e recentes emissões antropogênicas de gases efeito estufa são as mais altas na história", e aponta como causa principal a "concentração atmosférica de dióxido de carbono, metano e óxido nitroso [que são] sem precedentes pelo menos nos últimos 800 mil anos." "Finalmente, note-se que o referido relatório corrobora as projeções inauguradas do primeiro relatório do IPCC, datado de $1990 .{ }^{13}$ A esse respeito, observa-se adicionalmente um aumento no teto para a maior temperatura esperada - em 1990 a projeção era de 4,5 graus Celsius ${ }^{14}$, enquanto, no documento de 2014, esse valor subiu para 6,4 graus Celsius.

É nesse cenário que, de forma paulatina, opera-se uma ampliação dos intérpretes do Antropoceno. Em relação aos temas-quadro, convencionalmente associados

atividades humanas das últimas seis décadas foram responsáveis por $75 \%$ do incremento histórico nas emissões de dióxido de carbono. Crutzen e colaboradores denominam esse período grande aceleração em vista da velocidade e projeção global da atividade transformativa e exploratória do sistema Terra além do poder destrutivo do labor econômico globalizado. Iniciado em 2015, o particular apelo que o terceiro estágio desperta deve-se ao elevado grau de incerteza da escala e das consequências futuras. O uso do termo incerteza aduz um frágil quadro de prognose mediante o auxílio da técnica. (CRUTZEN, Paul; STEFFEN, Will; MCNEILL, John. The anthropocene: are humans now overwhelming the great forces of nature? Ambio, Estocolmo, v. 36, n. 8, p. 614-621, 2007.)

10 CRUTZEN, Paul; STOERMER, Eugene. The "anthropocene". Global Change Newsletter, n. 41, p. 17-18, 2000.

11 ALLEN, Myles et al. Climate change 2014 synthesis report. Approved summary for policymakers. International governmental synthesis report. Fifth assessment synthesis report. 2014. Disponível em: <http://www.ipcc.ch/report/ar5/wg2/>. Acesso em: 03 dez. 2015.

12 ALLEN, Myles et al. Climate change 2014 synthesis report. Approved summary for policymakers. International governmental synthesis report. Fifth assessment synthesis report. 2014. Disponível em: <http://www.ipcc.ch/report/ar5/wg2/>. Acesso em: 03 dez. 2015. p. 3-4. (Tradução nossa)

13 INTERGOVERNMENTAL PANEL ON CLIMATE CHANGE. IPCC Overview. 1990. Disponível em: <http://www. ipcc.ch/publications_and_data/publications_and_data_reports. shtml\#1>. Acesso: 03 dez. 2015. p. 52.

14 INTERGOVERNMENTAL PANEL ON CLIMATE CHANGE. IPCC Overview. 1990. Disponível em: <http://www. ipcc.ch/publications_and_data/publications_and_data_reports. shtml\#1>. Acesso em: 03 dez. 2015. p. 52. 
com o Antropoceneo, compete mencionar, dentre outros, a (cada vez mais realista) perspectiva de um futuro incerto e em escalas desconhecidas para as gerações porvir ${ }^{15}$, as transformações nas relações entre os seres humanos e o ambiente, os esforços teóricos e institucionais de remediação dos impactos climáticos, o descompasso entre as vias de cooperação internacional e a aceleração dos impactos climáticos para além-fronteiras, a identificação das origens da era geológica, e, finalmente, a desigualdade estrutural global que geraria variados níveis de participação e vulnerabilidade face aos efeitos climáticos. $^{16}$

A assimetria geográfica e sociopolítica dos impactos climáticos, em seu turno, vem sendo investigada a partir da explicitação dos possíveis reveses do tecnicismo das práticas de gerenciamento ambiental. É possível identificar a insistência em modelos e políticas regulatórias sustentadas na expectativa de mudanças ambientais em resposta ao quadro climático. Todavia, diante da ascensão da vulnerabilidade resultante da escala de ingerência humana, questiona-se se tais posturas respondem de forma adequada às exigências desse novo momento geológico. ${ }^{17}$

Foi, sobretudo, o artigo The Climate of History: Four Theses do historiador indiano Dipesh Chakrabarty, aquele que pode ser considerado o marco da chegada do Antropoceno às humanidades. Importante pensador pós-colonial cuja obra influenciou recentes debates historiográficos no Direito Internacional ${ }^{18}$, neste trabalho Chakrabarty postula um conjunto de teses que desafiam o estado da arte nas humanidades em geral. Convém explorar ao menos duas destas teses em razão das possíveis conexões com certas problemáticas historiográficas que tocam o Direito Internacional.

15 MARQUES, Clarissa. When the future becomes the present of the environmental crisis: the jurisprudence of the brazilian supreme court and the future dimension of the right to the environment. Revista de Direito da Cidade, Rio de Janeiro, v. 8, n. 2, p. 704-728, 2016. 16 Veja-se a recente coletânea dos editores HAMILTON, Clive; BONNEUIL, Christophe; GEMENNE, François (Eds.). The anthropocene and the global environmental crisis: rethinking modernity in a new epoch. New York: Routledge, 2015.

17 KIRSCH, Heitor Marcos; FILIPPI, Eduardo Ernesto. A dimensão ambiental do desenvolvimento: implicações para além do seu gerenciamento técnico-administrativo em um contexto de mudança climática. Revista de Direito Internacional, Brasília, v. 9, n. 3, 2012, p. 29-44.

18 Conferir o estudo de KOSKENNIEMI, Martti. Histories of international law: dealing with eurocentrism. Zeitschrift des MaxPlanck-Instituts für europä̈sche Rechtsgeschichte, v. 19, 2011, p. 176.
Em primeiro lugar, tem-se que "as explicações antropogênicas sobre a mudança climática lançam o colapso da tradicional distinção humanista entre história natural e história humana." ${ }^{19}$ Em segundo lugar, avança a proposição de que "a ideia de que o Antropoceno, esta nova Era Geológica quando humanos existem como uma força geológica, qualificam severamente as histórias da modernidade/globalização." ${ }^{20}$ Compete examinar cada uma destas proposições.

\subsection{Antropoceno e história: primeiras impressões}

No entendimento de Chakrabarty, a separação entre história humana e história natural entraria em colapso com o advento do Antropoceno. Sendo uma das características do pensamento histórico moderno - a consagração de modelos teóricos pautados pela separação entre a história humana e a história natural -, pode-se concebê-la como o reflexo racionalista-Iluminista Oitocentista de exaltação do humano que é potencialmente o mesmo em todo lugar. ${ }^{21}$

Por exemplo, na filosofia da história de Joseph Herder, a orientação teleológica da história - informada pela crença no progresso da razão humana enquanto força motriz e sentido histórico - faz-se presente na distinção entre a natureza e o homem. Uma vez que a especificidade de cada ambiente acrescerá um teor determinista ao grau de realização da justiça e da razão entre os povos, a natureza revela-se, sobretudo a partir da separação da esfera humana, como um obstáculo a ser superado. À história caberia o propósito de realizar “[...] nosso pequeno lugar tranquilo no grande sistema em que a razão e o bem, lutando embora com forças selvagens, criam todavia ordem a partir de sua natureza e permanecem no caminho da vitória." 22

Contornos filosóficos mais rígidos estão presentes na obra de historiadores como Robin Collingwood. Ao enaltecer a primazia do saber humano racional enquan-

19 CHAKRABARTY, Dipesh. The climate of history: four theses. Critical Inquiry, Chicago, v. 35, n. 2, 2009. p. 201. (Tradução nossa)

20 CHAKRABARTY, Dipesh. The climate of history: four theses. Critical Inquiry, Chicago, v. 35, n. 2, 2009. p. 207. (Tradução nossa)

21 CHAKRABARTY, Dipesh. Postcolonial studies and the challenge of climate change. New Literary History, Baltimore, v. 43, n. 1, p. 1-18, 2012.

22 HERDER, Johann Gottfried. Ideias para a Filosofia da História da Humanidade. In: GARDINER, Patrick. Teorias da história. 4. ed. Lisboa: Fundação Calouste Gulbenkian, 1995. p. 59. 
to componente da instrumentalização do ambiente e dos (não)saberes alijados dos processos modernos, para Collingwood a tarefa do historiador é sensivelmente diversa daquela do cientista natural. Enquanto o primeiro se vale do pensamento a fim de reconstruir a experiência passada, este último ocupa-se da identificação de leis naturais aptas a explicar determinado evento. Isto implica que os processos naturais são intrinsicamente distintos e não se inserem nas veredas do conhecimento histórico contemplado pelo historiador. Consoante expõe, "não pode existir história acerca daquilo que não é experiência [...] não há, portanto, nem pode haver, história da natureza, quer enquanto percebida quer enquanto pensada pelo cientista." ${ }^{23}$

$\mathrm{Na}$ primeira e fundante proposição de Chakrabarty, o Antropoceno irradiaria variados graus de instabilidade na direção das interações da vida humana com o ambiente. Não é sem razão, portanto, que cientistas como Crutzen e Stoermer propõem abordar o tema-quadro mediante a adoção do entendimento de que a humanidade existe e atua tal qual uma força geológica, e não somente como agentes biológicos individuais.

A razão jaz no porque da denominação força geológica: em nossa capacidade de agir coletivamente e historicamente, quando nos tornarmos numerosos e inventamos tecnologia "em uma escala suficientemente grande para impactar o planeta em si." ${ }^{24}$

Para Chakrabarty, o Antropoceno impacta o universo dos historiadores quando estes se deparam com o questionamento da possibilidade da existência de uma história humana diferenciada da história natural; por isso, o colapso dessa separação desestabiliza a possibilidade conceitual de uma história humana. É nesse preciso sentido que Isabelle Stengers interpreta a intrusão de Gaia como o "suscetível agenciamento de forças indiferentes aos nossos pensamentos e aos nossos projetos", que se faz transcendência, portanto apartada da história humana. ${ }^{25}$

Ademais, a extensão das projeções sobre as consequências das mudanças climáticas antropogênicas está situada em um estrato temporal que é estranho às con-

23 COLLINGWOOD, Robin George. A história como re-presentação da experiência passada. In: GARDINER, Patrick. Teorias da História. 4. ed. Lisboa: Fundação Calouste Gulbenkian, 1995. p. 312. 24 CHAKRABARTY, Dipesh. The climate of history: four theses. Critical Inquiry, Chicago, v. 35, n. 2, 2009. p. 207. (Tradução nossa).

25 STENGERS, Isabelle. No tempo das catástrofes: resistir à barbárie que se aproxima. São Paulo: Cosac Naify, 2015. p. 41. cepções epistemológicas que conformam a existência humana na Modernidade. A esse respeito assinalaram Paul Crutzen e colaboradores que "impacto das atividades humanas correntes é projetado para incidir sobre longos períodos", e que, "devido às emissões antropogênicas antigas e futuras de $\mathrm{CO} 2$, o clima poderá se distanciar significativamente de seu comportamento natural pelos próximos 50.000 anos." 26

A referência a escalas temporais de tamanha vastidão, nas quais as atividades humanas desde a Revolução Industrial potencialmente atingirão a realidade das futuras sociedades, levou Chakrabarty a intuir que "a corrente crise [climática] pode precipitar um senso do presente que desconecta o futuro do passado ao situar tal futuro além do alcance da sensibilidade histórica." ${ }^{27}$ Não é de se estranhar, portanto, que pensadores como Bruno Latour ${ }^{28}$ e Isabelle Stengers ${ }^{29}$ propõem refletir sobre o Antropoceno a partir da aceitação da fusão do humano e natureza que cria seres híbridos, pós-naturais, produtos de uma já realidade transhumanista que se prestam a libertar a existência dos condicionamentos da nova era. Ou, ainda, numa proposta narrativa catastrofista da Era do Antropoceno, encenar-se-ia a gradual conformidade à realidade inescapável do declínio das condições existenciais, cenário distópico da humanidade "devorada pela Terra que ela traiu." 30

A segunda tese de Chakrabarty pode ser entendida tanto como um desdobramento quanto como um ponto de desestabilização do esforço de conceber a humanidade enquanto força telúrica ou geológica. Em análise, a narrativa histórico-progressista da associação entre

26 CRUTZEN, Paul; STEFFEN, Will; MCNEILL, John. The anthropocene: are humans now overwhelming the great forces of nature? Ambio, Estocolmo, v. 36, n. 8, p. 614-621, 2007. p. 615. (Tradução nossa)

27 CHAKRABARTY, Dipesh. The climate of history: four theses. Critical Inquiry, Chicago, v. 35, n. 2, 2009. p. 197. (Tradução nossa)

28 LATOUR, Bruno. Telling friends from foes in the time of the Anthropocene. In: HAMILTON, Clive; BONNEUIL, Christophe; GEMENNE, François (Eds.). The anthropocene and the global environmental crisis: rethinking modernity in a new epoch. New York: Routledge, 2015. p. $145-155$.

29 STENGERS, Isabelle. Accepting the reality of Gaia: a fundamental shift? In: HAMILTON, Clive; BONNEUIL, Christophe; GEMENNE, François (Eds.). The anthropocene and the global environmental crisis: rethinking modernity in a new epoch. New York: Routledge, 2015. p. 134-144.

30 BONNEUIL, Christophe. The geological turn: narratives of the anthropocene. In: HAMILTON, Clive; BONNEUIL, Christophe; GEMENNE, François (Eds.). The anthropocene and the global environmental crisis: rethinking modernity in a new epoch. New York: Routledge, 2015. , p. 17-31. 
o ideal moderno de liberdade e a dependência da base energética fóssil para o desenvolvimento da mesma, no transcurso dos últimos duzentos anos, poderia esbarrar, no Antropoceno, numa contradição essencial: a realização dos potenciais emancipatórios da humanidade é dependente do tipo de relação que a mesma humanidade empreende no ambiente que habita e onde se realiza.

A questão central é que tal correlação, paradoxalmente, pode ser a causadora do atual quadro climático. Somente as consequências do quadro climático para os humanos são capazes de explicar, sugere Chakrabarty, "os humanos como uma forma de vida e olhar a história humana como parte da história da vida neste planeta" ou seja, o Antropoceno diz respeito ao deslocamento histórico que a espécie humana vem levando a cabo desde a Revolução Industrial.

A sugestão de tratar a humanidade como espécie ilustra a dificuldade da tarefa de situar historicamente o colapso climático. No cerne da dificuldade reside a necessidade de "aproximar formações intelectuais que estão um tanto quanto em tensão umas com as outras: o planetário e o global, a história profunda e a história registrada, o pensamento da espécie e as críticas do capital." ${ }^{32}$ Tais aproximações parecem situar-se em planos temporais estranhos daqueles concebidos por nossas instituições políticas e nossa ideia de Modernidade. A esse tipo de instabilidade teórica Chakrabarty irá se referir por "condições paramétricas que resistem independentemente de nossas escolhas políticas" ${ }^{\text {"33 }}$; dito por outros termos, as consequências das ações humanas orbitam escalas geográficas e estratos temporais imprevisíveis.

No âmbito da equivalência da humanidade com a espécie, não há de se perder de vista um desdobramento relevante para a historiografia: a perspectiva de uma história universal subsumida pela ascensão da categoria espécie humana como força geológica e diante da qual "não existem botes salva-vidas para os ricos e privilegiados." 34 Consoante análise infra, no tocante à história do Direito Internacional, certos empreendimentos historiográ-

31 CHAKRABARTY, Dipesh. The climate of history: four theses. Critical Inquiry, Chicago, v. 35, n. 2, 2009. p. 213. (Tradução nossa)

32 CHAKRABARTY, Dipesh. The climate of history: four theses. Critical Inquiry, Chicago, v. 35, n. 2, 2009. p. 213. (Tradução nossa)

33 CHAKRABARTY, Dipesh. The climate of history: four theses. Critical Inquiry, Chicago, v. 35, n. 2, 2009. p. 219.

34 CHAKRABARTY, Dipesh. The climate of history: four theses. Critical Inquiry, Chicago, v. 35, n. 2, 2009. p. 221. ficos estabelecem pautas críticas às linhas evolutivas e progressistas de instituições e normas, advogando por agendas de reforma e resistência. ${ }^{35}$ Diferentemente, tal qual Chakrabarty sugere, o Antropoceno acena para uma inerente dimensão universal comum às historiografias pós-coloniais ou subalternas.

Em todo caso, o emprego do termo espécie por Chakrabarty não permanece isento de ponderações. Enquanto este, ao longo da argumentação pretendida, abrange toda a humanidade em um novo projeto comum, teóricos como Andreas Malm e Alf Hornborg sublinham o que classificam como excessiva e forçosa inclusão de todo um espectro de relações sociais e culturais que caracterizam as inúmeras formas de existência humana. Assim, os termos espécie ou humanidade, tratados de maneira irrefletida e abrangente, ultimamente conotam um projeto:

Transhistórico [...] para explicar uma ordem
qualitativamente nova na história" que, em seu
turno, pressupõe "a visão mundo das economias
modernas [...] que sistematicamente obscurece as
trocas assimétricas de recursos biofísicos do qual a
industrialização é dependente. ${ }^{36}$

A nota dissonante de Malm e Hornborg fundamenta a acusação de que os referidos termos importam uma carga de abstração e generalidade que afastaria a análise da politização do Antropoceno. Essa operação discursiva estaria cega às desigualdades globais desde estágios anteriores do capitalismo financeiro: desde 1850, os países capitalistas do Norte foram responsáveis pela emissão de $72,7 \%$ do dióxido de carbono atmosférico, apesar de representarem 18,8\% da população mundial; por outro lado, $45 \%$ da população mundial emitiram 7\% do total desse gás-estufa; em termos de variações per capita das emissões, o cidadão médio dos EUA atende por 500 vezes mais emissões que o cidadão médio da Etiópia, Chade, Afeganistão, Mali, Camboja ou Burundi. ${ }^{37}$

35 OKAFOR, Obiora Chinedu. Newness, imperialism and international legal reform in Our time: a TWAIL perspective. Osgoode Hall Law Journal, Toronto, v. 43, n. 1, p. 171-191, 2005; AL ATTAR, Mohsen; MILLER, Rosalie. Towards an emancipatory international law: the bolivarian reconstruction. Third World Quarterly, Abingdon, v. 31, n. 3, p. 347-363, 2010.

36 MALM, Andreas; HORNBORG, Alf. The geology of mankind? A critique of the Anthropocene narrative. The Anthropocene Review, v. 1, n. 1, 2014, p. 64.

37 ROBERTS, J. Timmons; PARKS, Bradley C. A Climate of injustice: global inequality, north-south politics, and climate policy. Cambridge: The MIT Press, 2007. p. 144-149. A título exemplificativo, o cidadão médio do EUA emite o total de dióxido de carbono equivalente a 90 cidadãos de Guinea Bissau, ${ }^{34}$ cidadãos congoleses, 14 cidadãos 
A realidade e as desigualdades da sociedade internacional, insistem Malm e Hornborg, foram deixadas de lado quando Chakrabarty defendeu a preponderância da categoria espécie como força geológica. Se, consoante argumentam, "as vulnerabilidades diferenciadas em todas as escalas da sociedade humana" são obscurecidas por esta narrativa do Antropoceno, é tarefa das humanidades desconstruir o teor abrangente do discurso:

\begin{abstract}
à medida que oclui as origens históricas do aquecimento global e afunda a economia fóssil em condições inalteráveis, 'o Antropoceno' é uma ideologia mais por descuido do que por intento, mais o produto da dominação da ciência natural no campo da mudança climática e, talvez, o enfraquecimento generalizado das abordagens críticas e estreitamento dos horizontes políticos no mundo pós-1989 do que algum apologismo malicioso. Ele não é necessariamente menos prejudicial por isso. Ele é um dentre vários alicerces teóricos que são não apenas analiticamente defectivos, mas também hostil à ação. ${ }^{38}$
\end{abstract}

Portanto, em relação às apreensões iniciais sobre a recepção do Antropoceno nas humanidades, destacam-se como relevantes para a investigação em curso - qual seja, sua aproximação com a historiografia do Direito Internacional - dois aspectos. O primeiro consiste na proposição de um novo momento, era, ou evento, apto a desencadear níveis de ruptura com o passado com o condão de inovar o entendimento histórico. Viu-se que a narrativa do Antropoceno é ancorada nas transformações impulsionadas pela Revolução Industrial; contudo, assim espera-se refletir, outras narrativas são não apenas possíveis, como, também, necessárias, à compreensão das variadas dimensões desse problema.

O segundo ponto diz respeito à vocação englobante do termo espécie. Esta repercute no saber histórico porquanto designa uma determinada condição universal que produziria a convergência de distintos tempos e narrativas. Nesse particular, a dimensão política do labor histórico responderia pela crítica à neutralidade ideológica já denunciada por Malm e Horborg.

O cenário dessa oposição de perspectivas sobre o Antropoceno recebe influências do passado anacroni-

colombianos e 10 cidadãos brasileiros. Note-se que, em relação aos países de maior renda per capita e mais elevado produto interno bruto, o cidadão médio dos EUA se equivalem a no máximo 3 cidadãos da França, Alemanha, Japão, Itália, Espanha e Rússia.

38 MALM, Andreas; HORNBORG, Alf. The geology of mankind? a critique of the anthropocene narrative. The Anthropocene Review, Liverpool, v. 1, n. 1, 2014. p. 67. (Tradução nossa) camente pensado, e, também, no que poderia ser considerado em esforço de percepção das limitações do pensamento histórico, procura estabelecer as balizas do conhecimento em determinado contexto. É neste universo que os desígnios teleológicos da história do Direito Internacional almejam compor o horizonte histórico do mesmo.

\section{HISTÓRIA DO DIREITO INTERNACIONAL: ANACRONISMO E CONTEXTUALISMO SOB AS CONDICIONALIDADES DO ANTROPOCENO}

Nas últimas duas décadas, tornou-se frequente a referência ao ressurgimento do interesse pela história do Direito Internacional. ${ }^{39}$ As razões dessa guinada para a história, sugere Martti Koskenniemi, em parte se explicam pela descrença nas narrativas de progresso que nutriram as instituições e normas internacionais, que se proliferam e têm seu escopo de atuação ampliado, a partir da década de 1990. Conflitos religiosos e sociais, em geral acompanhados por violência doméstica e internacional, impuseram freios ao esperado triunfo do espírito liberal desse mesmo período, irresolução a partir da qual deriva um "desapontamento que reflete na plausibilidade das narrativas herdadas." 40 Por outro lado, por meio do exame da história da disciplina, novas perspectivas para os problemas do presente poderiam iluminar os rumos da sociedade internacional. Nesse caso, o recurso ao passado busca ampliar o espaço de interpretações possíveis que, segundo George Galindo, incorporam uma atitude crítica conduzente a "uma multiplicidade de significados que muitas vezes convivem em um mesmo tempo histórico." ${ }^{41}$

A riqueza de abordagens históricas não apenas reforça a viabilidade desta tocada, como também cria as

39 Ver, por todos, KOSKENNIEMI, Martti. Histories of international law: dealing with eurocentrism. Zeitschrift des Max-PlanckInstituts für europäische Rechtsgeschichte, v. 19, p. 152-176, 2011; GALINDO, George Rodrigo Bandeira. Para que serve a história do direito internacional? Revista de Direito Internacional, Brasília, v. 12, n. 1, p. 339-354, 2015.

40 KOSKENNIEMI, Martti. Histories of international law: significance and problems for a critical view. Temple International and Comparative Law Journal, Philadelphia, v. 27, n. 2, 2013, p. 216. (Tradução nossa)

41 GALINDO, George Rodrigo Bandeira. Para que serve a história do direito internacional? Revista de Direito Internacional, Brasília, v. 12, n. 1, 2015, p. 343. 
condições para a proposição de novos eixos analíticos. Tal é o caso da recente ênfase no método histórico jusinternacionalista. Aqui interessam as análises a respeito do vasto legado historicista enraizado na disciplina desde o século XIX. Em sua extensa influência na composição da narrativa convencional da disciplina, o historicismo enfatiza o papel do Direito Internacional nas trilhas da evolução dos institutos jurídicos lado a lado com a sociedade internacional. ${ }^{42}$ Por esse mesmo diapasão, envereda-se o jurista na busca por verdades no passado da disciplina com a finalidade de identificar ou acrescer autoridade essencial para o argumento jurídico. $^{43}$

Ilustrativo desse ponto, Leo Gross escreve em 1948 sobre o "memorável lugar atribuído a ele [Westphalia] na evolução das relações internacionais." ${ }^{44}$ No curso das referências ao registro de três séculos desde que os Tratados de Westphalia sedimentaram as bases jurídicas cuja maturação atravessaria o século XIX e culminaria na codificação da Carta da ONU, o trabalho de Gross desenha linhas progressistas de institutos - no caso, a igualdade soberana e a ideia de vinculação de condutas a normas gerais - resguardados indispensáveis para que o Direito Internacional viesse a ser "interpretado como um direito de uma comunidade internacional constituindo uma ordem legal para os Estados existentes." ${ }^{\text {45 }}$

Segundo David Kennedy, ao reduzir a atividade do historiador do direito à investigação da procedência de regras ou institutos, o saber histórico - do tipo proposto pelo historicismo - tende a reforçar a imagem de uma disciplina imaculada, desprovida de contradições, que se renova para fazer-se apta a regular juridicamente a sociedade internacional. ${ }^{46} \mathrm{Tal}$ qual enfatizara Leo Gross, Westphalia sedimenta um permanente marco na narrativa que realça o distanciamento da religião e

42 OPPENHEIM, Lassa. The science of international law: its task and method. American Journal of International Law, Washington, v. 2, n. 2, p. 313-356, 1908.

43 GALINDO, George Rodrigo Bandeira. Para que serve a história do direito internacional? Revista de Direito Internacional, Brasília, v. 12, n. 1, p. 339-354, 2015.

44 GROSS, Leo. The Peace of Westphalia, 1648-1948. American Journal of International Law, Washington, v. 42, n. 1, 1948. p. 26. (Tradução nossa)

45 GROSS, Leo. The Peace of Westphalia, 1648-1948. American Journal of International Law, Washington, v. 42, n. 1, 1948. p. 40. (Tradução nossa)

46 KENNEDY, David. The disciplines of international law and policy. Leiden Journal of International Law, Leiden, v. 12, n. 1, p. 9-133, 1999. da raison d'état para a realização da razão universal em meio a garantias formais de igualdade soberana e estabilidade sistêmica. Já no século XX, escreve Kennedy, o progresso é viabilizado pela renovação desta narrativa, desta vez sob a égide de instituições flexíveis de governança que introduzem técnicas de manejo consideradas indispensáveis para a nova realidade globalizada.

Em tempo, o que Kennedy observa é que a complexidade do registro histórico tende a ser reduzida quando se adota, acrítica e irrefletidamente, leituras canônicas do passado da disciplina. A leitura histórica de Leo Gross é exemplar do tipo de métrica linear, progressista e evolucionista característica do historicismo, e que será revisitada por nichos de pensamento histórico de variadas estirpes.

Compete ater-se à discussão metodológica pertinente a uma vertente historiográfica de importante repercussão no Direito Internacional: a historiografia pós-colonial. A atitude crítica empregada por pós-colonialistas como Antony Anghie ${ }^{47}$ ou Balakrishnan Rajagopal ${ }^{48}$ virá a incidir em, pelo menos, duas posturas metodológicas relativas à percepção da história através do tempo e que impactam na maneira como o Direito Internacional é entendido. Por essa razão, procurar-se-á contrapor entendimentos anacrônicos da história do Direito Internacional às reflexões metodológicas inspiradas na metodologia contextualista, consoante registra a denominada Escola de Cambridge e um de seus maiores expoentes, Quentin Skinner. ${ }^{49}$

No entanto, é preciso perceber que o referido diálogo almeja identificar os alicerces para a reflexão do tema central ora perseguido, qual seja, a ascensão do Antropoceno como referencial à crítica historiográfica aplicada no Direito Internacional.

\subsection{O passado e seus sentidos para o direito internacional}

Antony Anghie e Balakrishnan Rajagopal figuram na historiografia do Direito Internacional na condição de representantes de uma coletividade denominada

47 ANGHIE, Antony. Imperialism, sovereignty and the making of international law. Cambridge: Cambridge University Press, 2004.

48 RAJAGOPAL, Balakrishnan. International law from below: development, social movements and third world resistance. Cambridge: Cambridge University Press, 2003.

49 SKINNER, Quentin. Meaning and understanding in the history of ideas. History and Theory, Middletown, v. 8, n. 1, p. 3-53, 1969. 
TWAIL (Third World Approaches to International Law). O projeto de TWAIL sustenta-se na premissa segundo a qual as experiências de opressão, subdesenvolvimento e violência sentidas pelos povos subalternizados do Terceiro Mundo não podem ser dissociadas do aparato normativo e institucional do Direito Internacional. Uma elaborada enunciação desta premissa fundacional foi lavrada por Makau Mutua:

O Terceiro Mundo é mais verdadeiramente uma corrente de experiências históricas similares que corta virtualmente todas as sociedades nãoEuropeias e que deram origem a uma voz particular, uma forma de conscientização intelectual e política. O termo Terceiro Mundo é diferente de menos desenvolvido, suscetivel a crises, em processo de industrialização, em desenvolvimento, subdesenvolvido ou do Sul porque ele corretamente captura a dialética oposicional entre o Europeu e o não-Europeu, e identifica a pilhagem do segundo pelo primeiro. Ele [o termo] situa o estado de crise do mundo na ordem global que o Ocidente criou e dominou. [...] o termo é historicizado como parte de um paradigma estratégico de resistência e libertação. ${ }^{50}$

Para TWAIL, o Direito Internacional é percebido como o produto de uma longa história de trocas assimétricas envolvendo os povos subalternizados - o Terceiro Mundo tal qual conceituado por Mutua - e os povos do centro do sistema-mundo. Além de um projeto político de transformação da realidade internacional abrangendo uma multiplicidade de sujeitos e perspectivas $^{51}$, sua justificativa passa pelo esforço de entendimento de que TWAIL pode também ser compreendido em termos de crítica histórica. A esse respeito, atente-se para os elementos historiográficos de duas importantes obras, Imperialism, Sovereignty and the Making of International Law, de Antony Anghie, e International Law from Below: Development, Social Movements and Third World Strategy, de Balakrishnan Rajagopal.

50 MUTUA, Makau. What is TWAIL? proceedings of the 94th annual meeting of the american society of international law. 2000. Disponível em: <http://papers.ssrn.com/sol3/papers.cfm?abstractid=1533471 > . Acesso em: 05 abr. 2012. (Tradução nossa. Destaques no original).

51 Conferir a proposta de reconstrução do Direito da Integração inspirada em TWAIL, com foco no contexto das Américas: AL ATTAR, Mohsen; MILLER, Rosalie. Towards an emancipatory international law: the bolivarian reconstruction. Third World Quarterly, Abingdon, v. 31, n. 3, p. 347-363, 2010. Já para uma análise do potencial emancipatório de TWAIL no âmbito do reconhecimento da diversidade dos povos originários latino-americanos, conferir o estudo de FRANCO, Fernanda Cristina de Oliveira. Oportunidades e desafios das TWAIL no contexto latino-americano a partir das perspectivas dos povos indígenas ao direito internacional. Revista de Direito Internacional, Brasília, v. 12, n. 2, p. 226-244, 2015.
No caso de Anghie, o Direito Internacional encontra suas origens modernas nas proposições jurídicas do Dominicano Francisco de Vitoria. ${ }^{52}$ As assimetrias do encontro colonial foram legitimadas pela amplitude e generalidade do jus gentium de Vitoria. Anghie sugere que o teor universalizante do jus gentium inclui os povos originários Americanos apenas na condição de receptáculos das tradições Europeias. A operação eurocêntrica de criação do Direito das Gentes deu-se às expensas das alteridades dos povos originários: os institutos jurídicos aplicáveis ao comércio, à guerra e à propriedade sustentam-se em premissas particularistas, porquanto consistiam em representações jurídicas de práticas culturais específicas, e não universais. Nesse elaborado sistema jurídico "a identidade espanhola tanto é externalizada, no que ela age como a base das normas do jus gentium, quanto é internalizada no que ela representa a autêntica identidade do Índio." ${ }^{53}$

O ponto central do argumento de Anghie retornará em seu exame do instituto da soberania, o qual permeia a totalidade do estudo. A título de ilustração, Anghie conecta as práticas colonialistas e imperialistas do século XIX - e aqui despontam a doutrina da terra nullius e os regimes diferenciados de soberania aplicáveis às nações não civilizadas - com determinadas instituições internacionais - a Organização Mundial Comércio, o Banco Mundial ou a própria estrutura Onusiana - atuantes no Século XXI, trajetória da institucionalização de mecanismos de exploração e violência. A história da soberania, desde o jus gentium de Vitoria até o Sistema de Mandatos da ONU, é descrita por Anghie como o "processo pelo qual Estados não-Europeus são classificados como carentes de soberania e então excluídos da família das nações e do direito." 54

52 No entendimento de Paulo Emílio V. Borges de Macedo, a uma justa apreciação do legado de Vitoria procuraria reconhecer aspectos desse jurista - seu engajamento tomista e sua nacionalidade espanhola - que dotariam seu jus gentium de características únicas. $\mathrm{O}$ mito de que Vitoria seria o primeiro fundador do Direito Internacional foi construído a partir de seu prestígio intelectual resgatado no começo do século XX por expoentes como James Brown Scott, mas que, ao selecionar elementos específicos de tão complexo pensador, termina por deslocá-lo de seu tempo. MACEDO, Paulo Emílio Vauthier Borges de. O mito de Francisco de Vitória: defensor dos direitos dos índios ou patriota espanhol? Revista de Direito Internacional, Brasília, v. 9, n. 1, p. 1-13, jan./jul. 2012.

53 ANGHIE, Antony. Imperialism, sovereignty and the making of international law. Cambridge: Cambridge University Press, 2004. p. 23. (Tradução nossa)

54 ANGHIE, Antony. Imperialism, sovereignty and the making of international law. Cambridge: Cambridge University Press, 2004. p. 
Neste trabalho, uma janela liga o passado ao presente: o jus gentium de Vitoria inaugura uma longa história de exploração e injustiça. Uma constante histórica em permanente adaptação e aperfeiçoamento, para Anghie a violência colonial do Direito Internacional ganha relevo com o escrutínio da formação histórica da disciplina. Se uma visão anacrônica da história é adotada pelo autor com o propósito de denunciar as continuidades normativas e institucionais ligadas às violências do presente, o mesmo poder-se-ia afirmar acerca do projeto de Rajagopal. Em tempo, este último não apenas partilha marcos historiográficos próximos dos de Anghie, como também contempla outras frentes de reflexão.

A ênfase no Terceiro Mundo como protagonista no Direito Internacional proporciona a Rajagopal a inserção da categoria política resistência na história da disciplina. Para o autor, a história desta se caracteriza pela ausência de narrativas de resistência tais quais, e este é seu objeto de estudo, aquelas protagonizadas pelos movimentos sociais.

Não é o caso de afirmar que a história do Direito Internacional não se revelaria sensível à resistência política. A questão de maior apelo é o modo de operação e de reprodução de artefatos institucionais e também de normas criadas de acordo com os mesmos processos antevistos por Anghie, mas que, na perspectiva de Rajagopal, excluem, transformam ou reprimem a resistência do campo histórico de formação da disciplina. Tendo isto em mente, assinala que "é plausível argumentar que no direito e nas relações internacionais as condições sob as quais 'consensos espontâneos' podem ser manufaturados são tão, se não mais importantes, que o exercício de mecanismos de coação forçada." ${ }^{55}$

Com base em Rajagopal, nota-se que a história do Direito Internacional habita um universo de práticas discursivas pouco problematizadas. Não tanto uma coincidência, veio a ser exemplar para o presente a recente notícia de que o Banco Mundial deixará de utilizar as designações "desenvolvidos" ou "em desenvolvimento" para classificar os Estados em seus relatórios e demais documentos. ${ }^{56}$ É exemplar porque, ainda que

101. (Tradução nossa)

55 RAJAGOPAL, Balakrishnan. International law from below: development, social movements and third world resistance. Cambridge: Cambridge University Press, 2003. p. 18. (Tradução nossa)

56 BANCO MUNDIAL. The 2016 edition of World Development Indicators is out: three features you don't want to miss. Disponível em: <http://blogs.worldbank.org/opendata/2016-edition-world- o emprego de classificações para os Estados não seja uma novidade, deve-se ponderar se a continuidade, a descontinuidade e a transformação das classificações diriam respeito ao saber histórico jusinternacionalista construído em bases eurocêntricas.

É importante perceber que o campo historiográfico comporta usos e construções relacionadas à legitimação de formas de dominação. E este aspecto sinaliza uma integração da dimensão do labor historiográfico propagado por TWAIL. Trata-se da persistente continuidade, institucionalizada e normalizada, de um passado a acometer o presente com graus de colonialismo muito próximos do sentido que o geógrafo Derek Gregory atribui ao termo presente colonial. A perspectiva de uma dinâmica histórica que, no seu entender, consagra o avanço da Razão pelas trilhas do tempo homogêneo e vazio, também viabiliza a confecção de hierarquias valorativas problemáticas sobre ótima emancipatórias como TWAIL.

Plural e sempre contestada, cortada por múltiplas temporalidades e espacialidades, a história colonial faz-se presente porque as constelações de poder, conhecimento e geografia colonizam as vidas por todo o mundo. Elas não estão confinadas aos legatários dos antigos impérios e metrópoles. O nível de operação de sua influência nas práticas historiográficas exige uma postura diversa do historiador e do método histórico. A atividade do historiador deve ser, assim sublinha Gregory, "uma maneira de reconhecer as formas pelas quais tantos de nós (e aqui eu me incluo) continuam a pensar e a agir de formas que estão tingidas pelas cores do poder colonial. ${ }^{57}$

A conexão passado-presente também foi objeto da reflexão de George Galindo acerca dos possíveis sentidos de se ater à história do Direito Internacional. Colonialismo e eurocentrismo, uma vez inseridos nos debates da história da disciplina por via de movimentos como TWAIL, contribuem para tornar visível o sofrimento de sujeitos através do tempo. Ademais, o passado é refletido na confecção da agenda do tempo presente em que a história do Direito Internacional faculta a "opção por um direito internacional diferente." 58 Nessa

development-indicators-out-three-features-you-won-t-want-miss $>$. Acesso em: 18 maio 2016.

57 GREGORY, Derek. The colonial present. Oxford: Blackwell Publishing, 2004. p. 19. (Tradução nossa)

58 GALINDO, George Rodrigo Bandeira. Para que serve a história do direito internacional? Revista de Direito Internacional, Bra- 
toada, destaca-se um dever ético dos historiadores, em que a multiplicidade de narrativas históricas, métodos e correntes teóricas assistem na consciência de que "uma ética de responsabilidade para o historiador do direito internacional deve significar não apenas fiar-se em regras rigorosas da pesquisa historiográfica, mas também visualizar a possibilidade de mundo diferente." 59

\subsection{Metodologias historiográficas em diálogo}

Da mesma maneira que a responsabilidade ética do labor historiográfico está associada à reflexão trazida pela vívida imagem do passado colonial e das práticas eurocêntricas ao longo da história, uma dimensão adicional a respeito da metodologia historiográfica atrai a atenção dos internacionalistas. A esse respeito, nos últimos anos, alguns dos mais relevantes trabalhos na seara historiográfica não deixaram de enfrentar um amplo espectro de problemas relacionados à proposição metodológica essencial de TWAIL: o conhecimento do passado conduzido a partir do ponto de vista do tempo do historiador. ${ }^{60}$

Assim, algumas das objeções à proposta historiográfica de TWAIL nascem da repercussão do denominado método contextual entre os internacionalistas. Um destacado conjunto de historiadores de Cambridge no final da década de 1960 já acenava para uma renovação do método historiográfico não somente para aparelhar o

sília, v. 12 , n. 1,2015 , p. 351.

59 GALINDO, George Rodrigo Bandeira. Para que serve a história do direito internacional? Revista de Direito Internacional, Brasília, v. 12, n. 1, 2015, p. 352.

60 Conferir, por todos, KOSKENNIEMI, Martti. Victoria and us: thoughts on critical histories of international law. Zeitschrift des Max-Planck-Instituts für europäische Rechtsgeschichte, Munique, v. 22, p. 119-138, 2014; KOSKENNIEMI, Martti. Histories of international law: significance and problems for a critical view. Temple International and Comparative Law Journal, Philadelphia, v. 27, n. 2, p. 215-240, 2013; JAY, Martin. Historical explanation and the event: reflection on the limits of contextualization. New Literary History, Baltimore, v. 42, n. 4, p. 557-571, 2011; GALINDO, George Rodrigo Bandeira. Para que serve a história do direito internacional? Revista de Direito Internacional, Brasília, v. 12, n. 1, p. 339-354, 2015; HUNTER, Ian. Global justice and regional metaphysics: on the critical history of the law of nature and nations. In: DORSETT, Shaunnagh; HUNTER, Ian (Eds.). Law and Politics in British Colonial Thought: transpositions of empire. New York: Palgrave Macmillan, 2010. p. 11-30; ORFORD, Anne. The past as law or history? the relevance of imperialism for modern international law. IILJ Working Paper 2012. Disponível em: <http://www.iilj.org/publications/documents/IILJ20122OrfordFINALrevisedtoreflectupdatededitors.pdf $>$. Acesso em: 30 nov. 2014. labor histórico com ferramentas mais aptas a lidar com a complexidade que a caracteriza, mas também com o intuito de evitar as disfunções anacrônicas que a interpretação textual produzira. Contribuindo para a vertente denominada bistória das ideias, é nos confins desse recorte que Quentin Skinner avançou suas teses seminais acerca da aptidão da interpretação contextual para superar os vícios da análise exclusivamente textual.

Em síntese, Skinner sugere que a adequada apreensão do contexto em que se insere determinado pensador, ideia ou instituto exigirá a atenção às possibilidades comunicativas disponíveis para aqueles atores porventura envolvidos. Isto porque, no ato de enunciar algo (uma ideia, por exemplo), estarão implícitas possibilidades de descoberta de sentidos que modificariam a compreensão do enunciado. Ao considerar o ato de escrever um texto uma autêntica ação política, ou seja, um ato inclinado a persuadir a audiência através de argumentos atinentes à natureza do saber e das ordens social e política, Skinner rejeita a possibilidade de compreensão do passado com base em premissa de que o tempo do intérprete é mais evoluído e, portanto, mais adequado à análise de fatos pretéritos. ${ }^{61}$

Essas ideias foram recebidas por historiadores do Direito Internacional e representam instrumentos para o exame de textos jurídicos canônicos no contexto da produção dos mesmos. Com isto, passa a ser cada vez mais significativo, em termos metodológicos, que a interpretação das ideias de determinado jurista deva ter como referência uma dada ação o que o mesmo preferia realizar em seu universo político e profissional. A esse respeito, o anacronismo fundacional da crítica historiográfica pós-colonial de Anghie e de Rajagopal poderia ser descrito como a tentativa de imputar à obra de Francisco de Vitoria e outros um conjunto de sentidos e referências - colonialismo, imperialismo, opressão - tanto impossíveis de serem atribuídos com certeza aos seus atos de fala, quanto problemáticos porque derivados da matriz analítica do intérprete que vislumbra cinco séculos de história sob um viés particularista. ${ }^{62}$

61 SKINNER, Quentin. Meaning and understanding in the history of ideas. History and Theory, Middletown, v. 8, n. 1, p. 3-53, 1969. 62 KOSKENNIEMI, Martti. Victoria and us: thoughts on critical histories of international law. Zeitschrift des Max-Planck-Instituts für europä̈sche Rechtsgeschichte, Munique, v. 22, p. 119-138, 2014. Pra um aprofundamento no controverso legado de Francisco de Vitoria, conferir MACEDO, Paulo Emílio Vauthier Borges de. O mito de Francisco de Vitória: defensor dos índios ou patriota espanhol? Revista de Direito Internacional, Brasília, v. 9, n. 1, p. 1-13, 2012. 
De todo modo, a adoção do método contextual corre em paralelo com a reflexão sobre seus postulados. Isto porque, ainda que o contextualismo possibilite a análise do passado do direito e dos vocabulários políticos, tais atividades não se dão sem dificuldades. Por exemplo, Martti Koskenniemi e Martin Jay identificam um primeiro problema designado relativismo histórico. É sabido que o método contextual, ao adotar a compartimentalização da história, impõe a separação entre o passado estudado e o presente do intérprete. O que poderia ser considerado uma abordagem antagônica ao anacronismo poderá ensejar, nas palavras do primeiro autor, um revés metodológico porquanto mostrar-se-ia indiferente, ou até mesmo facilitaria, ao "enfraquecimento dos esforços para se encontrar padrões na história que poderiam responder pelas experiências atuais de dominação e injustiça." "3a Já para Jay, o relativismo histórico aproxima-se do relativismo cultural tendente ao mesmo afastamento de julgamentos éticos. ${ }^{64}$

Outra questão diz respeito à constatação de que os critérios para a delimitação do contexto frequentemente partem de momentos que antecedem o contexto em questão. As intenções das denominadas ações políticas a que Skinner fez menção podem ultrapassar o contexto em tela e adentrar outras demarcações temporais. Por isso, Koskenniemi sugere que a atividade de delimitação do contexto ideal guarda relevante teor de anacronismo, uma vez que o historiador deve necessariamente fazer escolhas, recortes e enquadramentos. Por meio dessas atividades, no caso de Vitoria, está-se "necessariamente enquadrando o mundo de Vitoria em razão das ideias atuais acerca da parcela do arquivo que é relevante e aquela que não é, e como a relação das mesmas deve ser entendida." ${ }^{65}$ A construção do contexto deve muito às intenções do historiador que implicam, por sua vez, um sentido "do que é interessante ou relevante boje e o que não é."

63 KOSKENNIEMI, Martti. Victoria and us: thoughts on critical histories of international law. Zeitschrift des Max-Planck-Instituts für europäische Rechtsgeschichte, Munique, v. 22, p. 119-138, 2014. p. 124. (Tradução nossa)

64 JAY, Martin. Historical explanation and the event: reflection on the limits of contextualization. New Literary History, Baltimore, v. 42, n. 4, p. 557-571, 2011.

65 KOSKENNIEMI, Martti. Victoria and us: thoughts on critical histories of international law. Zeitschrift des Max-Planck-Instituts für europäische Rechtsgeschichte, Munique, v. 22, p. 119-138, 2014. p. 125. (Tradução nossa)

66 KOSKENNIEMI, Martti. Victoria and us: thoughts on critical histories of international law. Zeitschrift des Max-Planck-Instituts für
Um último agrupamento de objeções pode ser encontrado no historiador Francis Oakley quando assinala duas reservas gerais ao projeto de Skinner. Primeiramente, o método contextual omite aquilo que em seu entendimento corresponde à continuidade do saber histórico. Sem este sentido de continuidade, o fazer histórico estritamente contextualizador estaria limitado à busca por sentidos que o autor do texto possa ter pretendido transmitir. Talvez mais problemática venha ser a possibilidade de que determinados autores tenham mais em comum com as ideias de indivíduos que os precederam do que com contemporâneos de seu tempo.

A segunda ressalva de Oakley remete à caracterização de uma tradição que responde pelo sentido de predicamento da vida humana independente das variadas formas pelas quais este é entendido ao longo do tempo. Aqui, Oakley aponta um amplo enquadramento da historiografia ocidental:

[...] não uma tradição centrada em valores ou
crenças partilhadas, mas um discurso argumentativo
articulado em um conjunto de questões acerca de
preocupações comuns e refletidas na autoridade de
um corpo literário definidor de problemas e que
profere uma gama de soluções. ${ }^{67}$

O peso da tradição a que Oakley se refere reverbera na consideração de Koskenniemi acerca do situacionismo do historiador e da dimensão ético-política do fazer histórico. O poder da tradição implica a asserção de que "não há contexto não-contextual, nenhuma 'visão a partir de lugar nenhum"'68; nesse aspecto, contextualismo se iguala ao historicismo, à ressalva de que aquele insiste na separação cronológica de momentos distantes e na falta de legitimidade de julgamentos éticos entre contextos.

Tais considerações convergem para a questão do enfraquecimento do teor crítico no âmbito da história, uma vez que promovem o afastamento das controvérsias do passado do espaço das discussões do presente; assim, ou o passado é blindado - intocável porque quase sagrado - ou representa algo insuscetível de menção por

europäische Rechtsgescbichte, Munique, v. 22, p. 119-138, 2014. p. 127. (tradução nossa, destaque no original)

67 OAKLEY, Francis. Politics and eternity: studies in the history of medieval and early-modern political thought. Brill: Leiden, 1999. p. 22. (Tradução nossa)

68 KOSKENNIEMI, Martti. Victoria and us: thoughts on critical histories of international law. Zeitschrift des Max-Planck-Instituts für europäische Rechtsgeschichte, Munique, v. 22, p. 119-138, 2014. p. 129. (Tradução nossa) 
ser politicamente irrelevante ao contexto de um dado momento presente.

A riqueza de análises históricas suscitadas, até o momento, poderá ser acrescida de reflexões derivadas da ascensão do Antropoceno nas ciências humanas. Defende-se o argumento de que o debate entre estas duas grandes variantes historiográficas investigadas nesta seção possui o mérito de acrescer novas interpretações para as formulações clássicas da historiografia internacionalista e de oferecer frutíferas perspectivas para a compreensão das demandas do presente. No entanto, tanto o passado anacronicamente representado no presente, quanto a defesa de contextos interpretativos estanques, serão potencialmente atingidos pela designada instabilidade característica do Antropoceno.

\section{VISÕES dO FUTURO NA HISTÓRIA: A EXPERIÊNCIA DO ANTROPOCENO E O HORIZONTE DO DIREITO}

Dear Matafele Peinam,

I want to tell you about that lagoon That lucid, sleepy lagoon lounging against the sunrise Men say that one day That lagoon will devour you

They say it will gnaw at the shoreline Chew at the roots of your breadfruit trees

Gulp down rows of your seawalls And crunch your island's shattered bones

They say you, your daughter And your granddaughter, too

Will wander rootless

With only a passport to call home

(Kathy Jetnil-Kijiner, Dear Matafele Peinam) ${ }^{69}$

Kathy Jetnil-Kijiner, poetisa nacional das Ilhas Marshall, dedica o poema desta epígrafe à filha Matafele Peinam. Em 2014, ano em que Kathy declamou o poema

69 JETNIL-KIJINER, Kathy. Dear metafele peinam. 2014. Disponível em: <https://jkijiner.wordpress.com/2014/09/24/united-nations-climate-summit-opening-ceremony-my-poem-to-mydaughter/>. Acesso em: 10 jan. 2016. na Assembleia Geral da ONU, Matafele Peinam não tinha mais que 6 meses de idade quando fora apresentada ao mundo nos braços do pai. A mensagem que Kathy legou à sua filha combina a emoção de uma nova vida que aborda em nosso mundo com a ameaça cada vez mais real de um futuro incerto para a geração da pequena Matafele: caso as projeções de aumento do nível dos oceanos em razão do colapso climático antropogênico se concretizem, seu país, assim como outras tantas nações da Oceania, deixarão de existir porque serão tomados inteiramente pelas águas.

A singela tristeza que transparece dos versos, dentre tantas reflexões possíveis e urgentes, permite situar o Antropoceno como integrante do cenário de investigação histórica do Direito Internacional. Trata-se de uma reflexão histórica por três razões centrais, a serem examinadas nesta última seção: (i) o Antropoceno diz respeito ao passado da sociedade internacional que repercute na agenda do presente; (ii) o Antropoceno introdur grau de instabilidade nas condiçoes de producão da história do Direito Internacional, (iii) trazendo incerteza para o futuro da sociedade internacional e desafiando a teleologia histórica do progresso.

\subsection{Uma defesa do anacronismo histórico}

Tal qual a reflexão sobre as origens modernas da sociedade internacional, inexiste acordo quanto às origens do Antropoceno - como visto, a narrativa predominante indica a Revolução Industrial. No detalhado exame de Lewis e Aslim a respeito da origem do Antropoceno, uma alternativa em particular pode potencialmente sedimentar frutíferos canais entre o Antropoceno e a historiografia crítica do Direito. Trata-se da bipótese da Orbis, palavra latina que designa mundo, e que concebe a ideia segundo a qual os impactos dos encontros das populações humanas do Antigo e Novo Mundo - "incluindo a homogeneização sem precedentes da biota terrestre" ${ }^{\prime 70}$ - vieram a fixar a primeira demarcação autenticamente global dos impactos das atividades antropocêntricas no ambiente.

O ponto principal a ser destacado é o de que as atividades antropogênicas, além de serem visíveis em processos de datação por extratos em amostras de gelo polar, podem ser constatadas a partir de uma combinação de ações tipicamente associadas ao colonialismo:

70 LEWIS, Simon; MASLIN, Mark. Defining the Anthropocene. Nature, Londres, v. 519, 2015. p. 175. (Tradução nossa) 
Além de alterar permanentemente e dramaticamente a dieta de quase toda a humanidade, a chegada dos Europeus às Américas também levou a um grande declínio nos números humanos. Estimativas populacionais regionais somam um total de 54 milhões de pessoas nas Américas em 1492, com recentes modelagens populacionais estimadas em 61 milhões de pessoas. Os números declinaram rapidamente para um mínimo de cerca de 6 milhões de pessoas em 1650 devido à exposição às doenças carregadas por Europeus, além de guerras, escravização e fome. A quase cessação da agricultura e a redução no uso do fogo que se sucedeu resultaram na regeneração de mais de 50 milhões de hectares de floresta, savanas arborizadas e áreas verdes com capacidade de retenção de carbono pela vegetação e solos estimadas em 5-40 Pg no transcurso de cerca de 100 anos. A aproximada magnitude e compasso do sequestro de carbono sugere que este evento contribuiu significativamente para o declínio observado no $\mathrm{CO}_{2}$ atmosférico de 7-10 p.p.m. [...] entre 1570 e 1620 documentado em dois núcleos de gelo Antártico de alta resolução. Esta queda no $\mathrm{CO}_{2}$ atmosférico é o mais proeminente aspecto, tanto em termos de velocidade de mudança e de magnitude, nos registros pré-industriais de $\mathrm{CO}_{2}$ atmosférico nos últimos 2000 anos. ${ }^{71}$

A bipótese da Orbis sugere que o Antropoceno não pode ser compreendido isoladamente, ou seja, assumindo um perspectivismo geológico apartado de seus desdobramentos sociais, culturais, biológicos e jurídicos mais amplos. Em decorrência, as referências aos impactos ambientais e humanos do denominado "encontro de dois mundos" e, portanto, do colonialismo simbolicamente inaugurado em 1492, consoante a leitura de Enrique Dussel, aproximam a tese de Lewis e Aslim da reflexão histórica típica de TWAILers como Anghie e Rajagopal.

Essa convergência temática poderia ser enunciada da seguinte maneira: a sincronia tempo-espacial entre a hipótese da Orbis e a relevância historiográfica do colonialismo e imperialismo para a história do Direito Internacional descortinam uma matriz de pensamento da mesma natureza que aquela combatida por TWAIL. Consequentemente, o fazer historiográfico pode inserir o Antropoceno na história do Direito Internacional com a peculiaridade de conjecturar continuidades usualmente associadas ao anacronismo, haja vista que a hipótese da Orbis empreende um olhar para o passado que rejeita a narrativa de Crutzen e Stoermer ao reforçar os laços do colapso climático com a modernidade

71 LEWIS, Simon; MASLIN, Mark. Defining the Anthropocene. Nature, Londres, v. 519, 2015. p. 175. (Tradução nossa) eurocêntrica. $^{72}$

Esse aspecto merece ser reforçado. A pesquisa de Lewis e Maslin vai ao encontro das abordagens pós-coloniais por situar os atos de violência colonial no núcleo das causas que potencialmente esclarecem o colapso climático. Diferentemente da datação sugerida por Crutzen e colaboradores ${ }^{73}$ - a Revolução Industrial e o começo do emprego de combustíveis fósseis em escalas sem precedentes -, a hipótese da Orbis propõe uma ideia muito diversa: o colonialismo como o primeiro marco do Antropoceno.

Os estudos de Anna Grear proporcionam um olhar mais apurado acerca da referida aproximação. De acordo com o argumento central, a teorização do Antropoceno precisa levar a sério a operação de estruturas hierárquicas inscritas na acepção anthropos, ou seja, na alusão à espécie humana. É preciso perceber que se trata de uma convergência argumentativa com Malm e Hornborg quando estes denunciam que, nas hierarquias do Antropoceno, existirão botes salva-vidas para uma seleta parcela da população. ${ }^{74}$

Para Grear, o Antropoceno exerce uma função específica na história do direito na medida em que se relaciona tanto com o espaço geográfico - o colapso climático - quanto com a estruturação de subjetividades no âmbito do direito - ligados ao self eurocêntrico como centro irradiador de injustiça, opressão e subalternização em direção às periferias. No anthropos, a posição do sujeito que conhece o objeto impõe-se sobre o mesmo tal qual o conhecimento moderno impõe-se sobre o senso comum:

[...] o argumento reside sobre estas continuidades discerníveis entre o Antropoceno - tanto como uma manifestação sobre uma época sob condições materiais sociais e bio-materiais concretas e como metáfora - e a imposição padronizada de hierarquias em operação dentro do antropocentrismo do direito. $^{75}$

A crítica historiográfica de TWAIL dialoga com os

72 CRUTZEN, Paul; STOERMER, Eugene. The "anthropocene". Global Change Newsletter, n. 41, p. 17-18, 2000.

73 CRUTZEN, Paul; STEFFEN, Will; MCNEILL, John. The anthropocene: are humans now overwhelming the great forces of nature? Ambio, Estocolmo, v. 36, n. 8, p. 614-621, 2007.

74 MALM, Andreas; HORNBORG, Alf. The geology of mankind? a critique of the anthropocene narrative. The Anthropocene Review, v. 1, n. 1, p. 62-69, 2014.

75 GREAR, Anna. Deconstructing anthropos: a critical reflection on 'anthropocentric' law and anthropocene 'humanity'. Law and Critique, Dordrecht, v. 26, n. 3, 2015. p. 227. (Tradução nossa). 
referidos quadrantes quando situa a narrativa da sociedade internacional em paralelo às demandas por reconhecimento do pluralismo e a denúncia de injustiças institucionalizadas e normatizadas. $\mathrm{O}$ ponto de conexão primordial entre esse esforço narrativo e aquele que pensadoras como Anna Grear sugerem para o Antropoceno é o da presença de hierarquias normativas estruturadas pela posição central de um sujeito que conhece e domina uma multiplicidade de formas de vida. Sob essa ótica, a presença de hierarquias é precondição para o Antropoceno: desigualdades intra-espécies foram tão essenciais para a inauguração da era da espécie humana quanto a injusta distribuição de recursos é condição para a existência da tecnologia moderna baseada em combustíveis fósseis.

No campo de estudos ambientais, constatam-se movimentos teóricos de aproximação da crítica pós-colonial ao pensamento ecológico. Um distinto aspecto a unir uma ampla variedade de eixos teóricos como o ecofeminismo, o ecocentrismo ou o ambientalismo pode ser descrito como a falha do pensamento e instituições modernas em situar ecologicamente formas de sociedade humanas, assim como as falhas em situar não humanos eticamente. Verifica-se, ademais, a recorrência de temas como antropocentrismo e eurocentrismo em crescente adesão crítica voltada para a desconstrução dos processos epistemológicos estruturantes da ascensão da racionalidade ocidental. ${ }^{76}$ Destarte, as trilhas históricas sujeitas à análise do pensamento ambiental revelam paralelismos com os parâmetros adotados pela historiografia TWAIL:

Se $[. .$.$] o triunfo dos colonizadores Anglo-Europeus$
sobre os povos originários da América do Norte (e
subsequentemente na América do Sul e Austrália)
foi afetada, no curso dos séculos seguintes, pelo
desarranjo ambiental - e, portanto, cultural -
em uma vasta escala, tais mudanças destrutivas
foram baseadas nas diferenças ontológicas e
epistemológicas entre as ideias que Europeus e
Indígenas possuíam acerca do humano e do animal
ser-no-mundo. ${ }^{77}$

A ideia segundo a qual a motivação da expansão im-

76 PLUMWOOD, Val. Decolonizing relations with nature. In: ADAMS, William; MULLIGAN, Martin (Eds.). Decolonizing nature: strategies for conservation in a post-colonial era. London: Earthscan Publications, 2003. p. 51-78.

77 DELOUGHREY, Elizabeth; HANDLEY, George. Introduction: toward an aesthetics of the earth. In: DELOUGHREY, Elizabeth; HANDLEY, George (Eds.). Postcolonial ecologies: literatures of the environment. Oxford: Oxford University Press, 2011. p. 11. (Tradução nossa) perial foi acentuada pelo desejo dos Estados coloniais em explorar os recursos dos territórios do mundo não Europeu não é de modo algum estranha ao universo da crítica pós-colonial de vertentes como TWAIL. De fato, Anghie enfoca a presença da racionalidade colonial nas práticas de companhias Ocidentais que "adquiriam concessões para a exploração de recursos minerais extremamente valiosos dentro da colônia, frequentemente em termos extremamente favoráveis."

A coordenação de esforços para resistir ao direito posto e modificá-lo para que atendesse às demandas do Terceiro Mundo, percebe-se que o processo de descolonização política da segunda metade do século XX abrangeu reformas que assegurassem não apenas o direito à autodeterminação dos novos Estados, como também a garantia de que a soberania dos mesmos se estenderia para o pleno controle dos recursos naturais. A tônica geral era garantir o direito ao desenvolvimento do Terceiro Mundo em uma matriz econômica mais favorável à equidade internacional. ${ }^{79}$

A carga anacrônica comum às abordagens acima contribui para a identificação de elementos históricos próximos às objeções atinentes à escassa problematização das hierarquias internas do Antropoceno. Enquanto a categoria espécie humana protagoniza a teorização de Chakrabarty, por meio da aproximação com as objeções às narrativas usuais das fundações da ordem jurídica internacional um processo histórico diverso toma forma. De um lado, as hierarquias humanas intra-espécie e, de outro lado, a construção juridicamente excludente de um anthropos abstrato e geral, criador de hierarquias inter-espécie, podem ser concebidos como componentes de um modelo de subjetividade legal construído historicamente.

Se, por meio anacronismo que esta leitura sugere, proceder-se-ia à refutação teórica do privilégio do tempo do intérprete resguardado como um tropo vacilante da metodologia historiográfica, o mesmo anacronismo potencialmente dialoga com o direito na medida em que a tarefa dos internacionalistas, nos termos que Anne Orford examinou a questão, "é pensar sobre como

78 ANGHIE, Antony. Imperialism, sovereignty and the making of international law. Cambridge: Cambridge University Press, 2004. p. 211. (Tradução nossa)

79 GATHII, James Thou. International Law and Eurocentricity. European Journal of International Law, Florença, v. 9, n. 1, p. 184-211, 1998. Neste trabalho, Gathii analisa a relação entre o Direito Internacional e eurocentrismo sob a tradição de TWAIL. 
conceitos se movem através do tempo e do espaço [...] o passado, em outras palavras, pode ser uma fonte de obrigações presentes." ${ }^{\text {" } 0}$ Vê-se que o debate em torno do anacronismo pode tomar direção diversa quando o foco recai sobre a atualidade intrínseca à construção dos argumentos jurídicos. Nesse sentido, o passado antropogênico da hipótese da Orbis faz-se presente e corrobora ou rejeita aspectos normativos dos problemas do presente, no tempo em que este se experimenta.

\subsection{Contexto histórico e incerteza no Direito Internacional}

Em exame do segundo eixo designado para essa seção final, cumpre inquirir acerca da aludida desestabilização do saber historiográfico. Para tanto, poderá ser relevante a retomada da discussão sobre a influência da metodologia contextual nos quadros da historiografia jusinternacionalista. A razão desta conexão - Antropoceno e contextualismo - decorre da incompreensão dos efeitos do colapso climático antropogênico e suas relações com a leitura da realidade contextualmente considerada. Uma vez que as objeções supracitadas iluminam aspectos controversos da adoção integral e acrítica do contextualismo, é a partir desse panorama que o Antropoceno introduz relevantes reflexões para a historiografia do direito.

A despeito das projeções futuras para a mudança climática, certas controvérsias começam a repercutir no Direito Internacional desse começo de século. Tal é o caso das discussões concernentes às prováveis consequências do aumento do nível do mar na escala concebida pelos recentes relatórios do IPCC - a mais recente estimativa do Painel menciona uma elevação de até 98 $\mathrm{cm}$, o que representa um considerável incremento sobre o relatório anterior, de 2007, com a expectativa de aumento de $59 \mathrm{~cm} .{ }^{81}$ Do mesmo modo, corroborando a necessidade de ultrapassar barreiras disciplinares que separam as ciências biológicas dos processos decisórios e

80 ORFORD, Anne. The past as law or history? the relevance of imperialism for modern international law. IILJ Working Paper 2012. Disponível em: <http://www.iilj.org/publications/documents/ IILJ20122OrfordFINALrevisedtoreflectupdatededitors.pdf> . Acesso em: 30 nov. 2014. (Tradução nossa)

81 ALLEN, Myles et al. Climate change 2014 synthesis report. Approved summary for policymakers. International governmental synthesis report. Fifth assessment synthesis report. 2014. Disponível em: < http://www.ipcc.ch/report/ar5/wg2/>. Acesso em: 03 dez. 2015. da regulação jurídica, Barros-Platiau et al atentam para a necessidade do uso "político e legal do conceito do Antropoceno para fins de mudanças comportamentais" tendo como caso de análise da estratégia brasileira de gestão dos recursos marinhos em contexto de aumento da complexidade da ordem internacional.

O Direito do Mar seria o primeiro grande ramo da disciplina a ser atingido pelo aumento do nível dos mares. Redefinições de linhas-base, a extensão das variadas zonas marítimas e a afetação dos limites das mesmas, ou mesmo a infiltração das mesmas linhas em sentido oposto, convergindo para os continentes, são exemplos dos tipos de consequências esperadas. ${ }^{83}$ Todavia, o aumento do nível dos mares abrange um rol temático mais extenso e complexo que esta breve enumeração relativa ao Direito do Mar. Davor Vidas, que estuda a aproximação do Antropoceno ao Direito Internacional, esclarece o alcance das esperadas consequências neste último:

No futuro não tão distante, questões importantes vão emergir a respeito da sustentabilidade destes aspectos do direito internacional, enquanto outros aspectos, tal qual a população do estado - e, por consequência, os direitos humanos - podem ganhar em proeminência e adquirir novas dimensões, que muito provavelmente vão demandar um profundo reexame dos paradigmas correntemente aceitos do direito internacional. ${ }^{84}$

Visto que aspectos centrais do Direito Internacional dependem de condições geográficas que são percebidas como constantes, mudanças significativas nessas

82 BARROS-PLATIAU, Ana Flávia et. al. Correndo para o mar no antropoceno: a complexidade da governança dos oceanos e a estratégia brasileira de gestão dos recursos marinhos. Revista de Direito Internacional, Brasília, v. 12, n. 1, 2015. p. 153.

83 O Final Report of the International Committee on Baselines under the International Law of the Sea de 2012, lavrado pela International Law Association, aponta a inadequação de disposições da Convenção de Montego Bay em vista das consequências da mudança climática. Tal é o sentido de uma das conclusões do referido relatório: “[...] the normal baseline is ambulatory, moving seaward to reflect changes to the coast caused by accretion, land rise, and the construction of human-made structures ... and also landward to reflect changes caused by erosion and sea level rise. Under extreme circumstances the latter category of change could result in total territorial loss and the consequent total loss of baselines and of the maritime zones measured from those baselines. The existing law of the normal baseline does not offer an adequate solution to this potentially serious problem." (INTERNATIONAL LAW ASSOCIATION. Final report of the international committee on baselines under the international law of the sea. 75th Conference. Sofia, 2012. Disponível em: <www. ila-hq.org/ en/committees/ index. cfm/cid/1028>. Acesso em: 25 maio 2016.) 84 VIDAS, Davor. Sea-level rise and international law: at the convergence of two epochs. Climate Law, Leiden, v. 4, n. 1, p. 70-71, 2014. (Tradução nossa) 
mesmas condições trariam repercussões significativas para a sustentabilidade da ordem jurídica internacional. Para Vidas, o atual quadro das normas internacionais referentes ao Direito do Mar não responderia à altura da instabilidade institucional e normativa envolvidas. Como resultado, em lugar da previsibilidade e da certeza até então em construção em sede jurisdicional ao longo das últimas décadas de litígios fronteiriços entre Estados, o cenário apresentado pelo colapso climático virá a sobrepor-se, desestabilizando as condições sobre as quais o direito pautou-se até então.

Enquanto a extensão soberana dos limites marítimos ressoa na doutrina e desperta para a reflexão de aspectos normativos correlatos, a ascensão do nível dos mares também atinge a própria compreensão da constituição do Estado. O Antropoceno poderá ser a era em que Estados efetivamente deixam de existir devido aos impactos do aumento do nível do mar. É o caso das Ilhas Marshall, terra natal da poetisa cujos versos inspiram a epígrafe desta seção. No Antropoceno, a perda de território é atribuída às mudanças na situação factual, e não em consequência de mudanças políticas, como é usualmente o caso e a prática no Direito Internacional..$^{85}$

Desse modo, descortina-se um complicador para a delimitação do contexto de interpretação dos debates jurídicos sobre o colapso climático e o Direito Internacional. Às tensões habituais ao cenário jurídico global - igualdade soberana no plano jurídico em oposição às diferenças políticas, militares, econômicas, culturais, dentre outras -, acresce-se o que Davor Vidas e colaboradores designaram por tensão antropogênica. ${ }^{86}$ Esse novo ponto de tensão advém da quebra das condições de estabilidade do Holoceno que possibilitaram a paulatina construção do aparato jurídico e político que regula as relações internacionais.

O Direito Internacional, em sua formatação atual, pode ser entendido como o produto de um processo histórico enquadrado em condições geológicas estáveis e previsíveis. O cenário que se desdobra será marcado pela procura por soluções para problemas novos - tal qual a questão dos Estados submersos -, porém consi-

85 VIDAS, Davor. Sea-level rise and international law: at the convergence of two epochs. Climate Law, Leiden, v. 4, n. 1, p. 70-84, 2014.

86 VIDAS, Davor; ZALASIEWICZ, Jan; WILLIAMS, Mark. What is the anthropocene: and why is it relevant for international law? Yearbook of International Environmental Law, Oxford, v. 25, n. 1, p. 3-23, 2015. derados sob uma matriz jurídica que terá na instabilidade um de seus mais evidentes atributos.

\subsection{Distopia: horizontes da teleologia histórica no Antropoceno}

O historiador germânico Reinhart Koselleck afirma que uma das tarefas da teoria da história é "delinear e estabelecer as condições das histórias possíveis, não as histórias mesmas. Trata-se de categorias do conhecimento capazes de fundamentar a possibilidade de uma história." $" 87$ Qual a relevância de se inquirir acerca das condições sine qua non do saber histórico? Quais relações poderiam ser tecidas entre as condicões das histórias possiveis no Direito Internacional e o Antropoceno? Inspirando-se na teorização de Koselleck, espera-se refletir sobre os condicionamentos de percepção do passado-presente a ressoarem na idealização do futuro no entendimento histórico e jurídico do Antropoceno.

Quando concebe a construção do saber histórico, Koselleck credita às categorias espaço de experiência e horizonte de expectativa a tarefa de conectar passado e futuro. Desse modo, antes de se pensar na história propriamente - fatos, processos, sujeitos etc. -, subjaz um movimento reflexivo preliminar de determinação do conhecimento histórico. Convém examinar, mesmo que de forma breve, as respectivas categorias.

Enquanto a experiência responde pelo passado atual, os acontecimentos próprios ou as experiências alheias que, por já terem sido incorporadas, podem ser lembradas, a categoria expectativa designa o futuro presente, o ainda-não que apenas pode ser previsto. Assim, uma experiência se diferencia por já "haver elaborado acontecimentos passados, é o poder torná-los presentes [...] incluir em seu próprio comportamento as possibilidades realizadas ou falhas." ${ }^{88}$ Diferentemente, uma expectativa opera nos quadrantes de um horizonte, "aquela linha por trás da qual se abre no futuro um novo espaço de experiência, mas um espaço que ainda não pode ser contemplado", e, de forma oposta, "a possibilidade de se descobrir o futuro, apesar de os prognósticos serem

87 KOSELLECK, Reinhart. Espaço de experiência e horizonte de expectativa: duas categorias históricas. In: KOSELLECK, Reinhart. Futuro Passado: Contribuição à semântica dos tempos modernos. Rio de Janeiro: Contraponto, 2012. p. 306.

88 KOSELLECK, Reinhart. Futuro passado: contribuição à semântica dos tempos modernos. Rio de Janeiro: Contraponto, 2012. p. 312. 
possíveis, se depara com um limite absoluto, pois ela não pode ser experimentada." ${ }^{89}$

Equívoco seria deduzir que o espaço de experiência é estático. Experiências superpõem-se, retroagem, cruzam-se, impossibilitando conclusões simplistas de que o futuro irá concretizar-se a partir da mera soma das experiências passadas. De modo diverso, experiências interagem com o horizonte futuro, o que significa dizer que a dinamicidade também é atributo do horizonte de expectativas quando se compreende que o futuro somente pode surpreender se não for esperado, isto é, se não for contido totalmente nas experiências passadas.

Desse modo, entre o espaço de experiência e o horizonte de expectativas existe um fluxo contínuo de trocas, de uma maneira que "o ganho de experiência ultrapassa então a limitação do futuro possível." ${ }^{\prime 90}$ Entretanto, talvez mais relevante para a discussão do Antropoceno possa ser a verificação de como experiência e expectativa dialogicamente produzem uma estrutura de prognóstico, ou seja, o tempo histórico que adquire relevância na construção de narrativas específicas sobre as conexões entre passado e futuro. $\mathrm{Na}$ intersecção entre passado e futuro, situa-se o contexto do intérprete do presente, um espaço de experiências conectado com o horizonte de expectativas.

Essa questão diz respeito à Modernidade. Nesta, a distância entre espaço de experiência e horizonte de expectativa alarga-se permanentemente. Explique-se: o espaço de experiências é defrontado com uma avalanche de inovações técnico-científicas em tempos acelerados, o que impossibilita sua experimentação enquanto passado. Ao mesmo tempo, fornece perspectivas das mais variadas para o design do horizonte de expectativas.

É importante destacar que a ideia progresso opera na concepção de futuro de um grande conjunto de ideias políticas e impacta diretamente na Modernidade. A construção moderna de tempo engendra uma completa reformulação na concepção escatológica de tempo que esteve a dominar os horizontes históricos do Ocidente ao longo da Idade Média. Enquanto a queda do Sacro Império Romano-Germânico contribuiu para a separa-

89 KOSELLECK, Reinhart. Futuro passado: contribuição à semântica dos tempos modernos. Rio de Janeiro: Contraponto, 2012. p. 311.

90 KOSELLECK, Reinhart. Futuro passado: contribuição à semântica dos tempos modernos. Rio de Janeiro: Contraponto, 2012. p. 313. ção entre a história sacra, a história humana e a história natural, o deslocamento do fim do mundo para os ramos da astrologia, e não da escatologia, correu em paralelo com a assunção do sistema Europeu de Estados soberanos nos marcos da Paz de Westfália em 1648. ${ }^{91}$

Assim, o tempo moderno acelerado acresce à história um sentido de porvir, um olhar para o futuro progressista ou utópico. Para tanto, relevante é o consideração de que "o significado de conceitos políticos (e legais) chave partiram da experiência acumulada para incorporar um olhar para frente." ${ }^{\prime 2}$ Este olhar para frente guarda estrita correspondência com a premissa de que a história relaciona-se com certos sentidos do tempo e com ideias que iluminam as instituições sociais para informar determinada teleologia na qual preceitos como destino, desígnio inteligente ou progresso sem fim respondem pelos por quês da humanidade. ${ }^{93}$

As referências às ideias de progresso e de teleologia no campo historiográfico tomam forma nos debates filosóficos do século XIX, um século que nasce das Revoluções Liberais e no qual a "história era concebida como um processo progressivo de gradativo aperfeiçoamento da humanidade, um processo cujo curso tornava a razão transparente para si mesma." ${ }^{\prime 94}$ No internacionalismo liberal, a influência da matriz kantiana nas análises historiográficas de juristas que alinharam o ideal de progresso ao Direito é visível particularmente na conformação de uma vocação universal para o Direito Internacional. Nos eixos da referida filosofia da história, a teleologia

91 KOSELLECK, Reinhart. Futuro passado: contribuição à semântica dos tempos modernos. Rio de Janeiro: Contraponto, 2012. Coube ao Estado-nação introduzir uma ruptura adicional no perspectivismo temporal Cristão, pois a política, a economia, o cidadão e, simultaneamente, o constitucionalismo e o direito moderno impõem uma métrica histórico-temporal específica, consoante se pode observar na tradição contratualista da passagem do estado de natureza para o estado civil ou nas tensões entre poder constituinte e poder constituído. (FASOLT, Constantin. The Limits of History. Chicago: University of Chicago Press, 2004.)

92 KOSKENNIEMI, Martti. Victoria and us: thoughts on critical histories of international law. Zeitschrift des Max-Planck-Instituts für europäische Rechtsgeschichte, v. 22, p. 119-138, 2014. p. 123. (Tradução nossa)

93 PEGORARO, Olinto A. Sentidos da história: eterno retorno, destino, acaso, desígnio inteligente, progresso sem fim. Petrópolis: Vozes, 2011.

94 TRÜPER, Henning; CHAKRABARTY, Dipesh; SUBRAHMANYAM, Sanjay. Introduction: Teleology and history: nineteenth-century fortunes of an enlightenment project. In: TRÜPER, Henning; CHAKRABARTY, Dipesh; SUBRAHMANYAM, Sanjay (Eds.). Historical teleologies in the modern world. Londres: Bloomsbury, 2015. p. 3-24. p. 6. (Tradução nossa) 
que concebia propósitos às instituições e normas pôde ser percebida, a título ilustrativo, no movimento de expansão da sociedade internacional no século XIX.

Esse tempo acelerado enquadrado no espaço de experiências foi alçado ao status de standard para as relações sociais, econômicas e culturais. Nesse particular, o progresso instaurou uma dinâmica imperial, assim poder-se-ia caracterizar os processos de hierarquização entre os povos avançados e aqueles atrasados em relação ao ideal de progresso experimentado pelos primeiros:

\begin{abstract}
O progresso reunia, pois, experiências e expectativas afetadas por um coeficiente de variação temporal. Um grupo, um país, uma classe social tinham consciência de estar à frente dos outros ou ultrapassá-los. Aqueles dotados de uma superioridade técnica olhavam de cima para baixo o grau de desenvolvimento dos outros povos, e quem possuísse um nível superior de civilização julgava-se no direito de dirigir esses povos. ${ }^{95}$
\end{abstract}

Nesse contexto, por meio da adoção do standard civilizatório Europeu, o Direito Internacional teve acrescido ideais de aprimoramento dos povos não civilizados ou bárbaros para as quais o reconhecimento soberano deveria ser merecido e os demais institutos jurídicos tais quais o Direito dos Tratados e o Direito da Guerra - eram aplicados de forma restrita, assimétrica e casuística. ${ }^{96}$ Tal momento já foi caracterizado por Koskenniemi como um projeto de juristas liberais preocupados em construir uma sensibilidade civilizatória universal amparada em fatos científicos - como, por exemplo, o darwinismo social ou a sociologia positivista - diante dos quais a legislação iria atuar. Não pode ser mera coincidência a adequação dessa plataforma normativa à cultivada hegemonia da cultura Ocidental. ${ }^{97}$

É importante perceber que o concerto derivado da sobreposição de conceitos políticos com entendimentos filosóficos acerca da história por vezes forma vívidas imagens de futuro da sociedade internacional. A partir de Koselleck, poder-se-ia dizer que o borizonte de expectativas é preenchido por ideias que pretendem exercer sua begemonia

95 KOSELLECK, Reinhart. Futuro passado: contribuição à semântica dos tempos modernos. Rio de Janeiro: Contraponto, 2012. p. 317.

96 GROVOGUI, Siba N'Zatioula. Sovereigns, quasi sovereigns, and africans. Minneapolis: Minnesota University Press, 1996.

97 KOSKENNIEMI, Martti. The gentle civilizer of nations: the rise and fall of international law 1870-1960. Cambridge: Cambridge University Press, 2001; AFONSO, Henrique Weil. A reconstrução histórica da diversidade no direito internacional. Rio de Janeiro: Lumen Juris, 2015. p. 285-352. no espaço de experiências. Por isto, quando se busca identificar as coordenadas teóricas de conceitos complexos como soberania, uma multiplicidade de leituras concorrerá, porquanto informarão a história sobre o passado, o presente e a perspectiva de futuro do instituto.

Vejam-se dois exemplos em que estas categorias se articulam para forjar uma determinada perspectiva de futuro, a primeira mais restrita, a segunda mais aberta em termos de horizontes de perspectiva. A afirmação do império de uma única potência no mundo pós 11/09 foi o elemento determinante para o que Richard Falk veio a considerar como principais modelos postulantes à ordem mundial pós-Westphaliana. Ao lado deste, Falk registra a ascensão das práticas de governança global, flexibilização de direitos e fortalecimento de atores não estatais. No primeiro caso, o unilateralismo dos EUA encarna o papel de protagonista a gerar um estado de guerras assimétricas, de enfraquecimento de instituições globais e de contínua classificação e eliminação de ameaças. No segundo caso, a utopia global de interdependência econômica, política e cultural se realizaria para preencher o espaço antes ocupado pelo anacrônico Estado-nação. Tais componentes, a um tempo, fortalecem a ambivalência normativa e institucional do mundo porvir, e, em um segundo momento, produzem um desfecho que inviabilizaria alternativas. ${ }^{98}$

Diferentemente, a intervenção de Hent Kalmo e Quentin Skinner nesse debate insiste que um único determinante não é suficiente para caracterizar o horizonte histórico definitivo, ou seja, que a complexidade histórica desautoriza conclusões definitivas. Para tanto, enfatizam a utilidade de se pensar, argumentativamente, sobre a soberania em vez de buscar por correlatos na experiência real: deve-se compreender a mudança conceitual e a vida política da linguagem em geral a fim de manter um diálogo permanente com a dimensão histórica da soberania. Uma vez que os usos de um conceito estão relacionados com conteúdos conceituais contingentemente situados, estes coexistem com outros possíveis conteúdos localizados em extratos temporais diversos, isto é, "vistos como sedimentos semânticos multicamadas a partir de uma acumulação de argumentos."

98 FALK, Richard. International Law and the Future. In: FALK, Richard; RAJAGOPAL, Balakrishnan; STEVENS, Jacqueline (Eds.). International law and the third world: reshaping justice. London: Routledge-Cavendish, 2008. p. 23-34.

99 KALMO, Hent; SKINNER, Quentin. Introduction: a concept in fragments. In: KALMO, Hent; SKINNER, Quentin (Eds.). Sov- 
Nesses termos, a história pode iluminar o presente

[...] não apenas produzindo similaridades e revelando as contínuas raízes da nossa maquiagem conceitual, mas também, e talvez ainda mais importante, pelo seu estranhamento, por nos fazer ater à multiplicidade de caminhos que nós não seguimos. ${ }^{100}$

Importa à reflexão histórica sua capacidade de situar contingencialmente as condições de produção dos discursos políticos e jurídicos porque é somente a partir de um distanciamento dos mesmos - aqui opera o "estranhamento" - que o horizonte de futuro desenhado por eles não equivalerá ao desfecho teleológico das possibilidades de agência histórica.

Finalmente, à luz destas considerações, questiona-se se o Antropoceno inaugura um horizonte de expectativas favorável à sociedade internacional. Situando-se as projeções de colapso climático no núcleo dos debates históricos aqui considerados, o futuro desenrola um cenário menos utópico do que o internacionalismo liberal ou até mesmo do mundo imaginado pela governança global. De fato, a aludida desestabilização trazida a cabo pelo Antropoceno não se limita tão somente ao problema de como situar as atividades antropogênicas em uma perspectiva histórica, com suas hierarquias e discursos mais próximos do escrutínio político e democrático, mas, talvez mais relevante para esta discussão, a presença de distopias históricas:

Os modernos [...] voam futuro adentro e olham
para trás, escapando do terrível sofrimento do
passado e da opressão, porém incapazes de ver a
destruição que os espera à frente. Para eles, o real
é o que foi deixado para trás, e o futuro é só aquilo
que o sujeito autônomo acaba por criar. Poucos
progressistas deram a volta ao encarar o futuro;
e pode-se ver porque, já que o progressista que
muda de curso não pode mais ser um progressista.
No Antropoceno, em adição ao passado do qual
buscamos escapar, temos agora um futuro que
queremos evitar; estamos apertados dos dois
lados, e todo novo projeto emancipatório deve
transcender a categoria progressista do passado. ${ }^{101}$

ereignty in fragments. the past, present and future of a contested concept. Cambridge: Cambridge University Press, 2010. p. 11. (Tradução nossa)

100 KALMO, Hent; SKINNER, Quentin. Introduction: a concept in fragments. In: KALMO, Hent; SKINNER, Quentin (Eds.). Sovereignty in fragments. the past, present and future of a contested concept. Cambridge: Cambridge University Press, 2010. p. 10. (Tradução nossa)

101 HAMILTON, Clive. Human destiny in the Anthropocene. In: HAMILTON, Clive; BONNEUIL, Christophe; GEMENNE, François (Eds.). The anthropocene and the global environmental crisis: rethinking modernity in a new epoch. New York: Routledge, 2015. p. 39.
As considerações de Hamilton desafiam a tradição progressista do Direito Internacional e contextualizam o Antropoceno como o ambiente da improvável realização das utopias históricas onde

Os iluminados entre nós desejam harmonia, sustentabilidade e cooperação, mas estas aspirações chocam com os cientistas do mundo que agora descrevem imagens vívidas do 'gigante enfraquecido' [...] de Gaia 'lutando' e buscando vingança. ${ }^{102}$

Similarmente, o alerta de Chakrabarty, aquele de que o poder geológico coletivo associado à espécie humana em decorrência da atividade antropogênica dos últimos séculos, inspira menos otimismo do que a crença no progresso que influenciou os internacionalistas do século XIX e que foi revivido no contexto da década de 1990:

Hoje, é precisamente a 'sobrevivência da espécie' em uma 'escala global' que está largamente em questão. Todo o pensamento político progressista, incluindo a crítica pós-colonial, terá de assimilar esta profunda mudança na condição humana. ${ }^{103}$

O Antropoceno ocupa um estrato temporal próprio, operando num tempo geológico projetado para um futuro em que as condições estáveis do Holoceno estão sendo substituídas pela incerteza dos efeitos das ações antropogênicas. Assim como futuros distópicos não são propriamente bem-vindos no universo das teleologias do Direito Internacional, a possibilidade de que a história humana se dissocie dos projetos de triunfo da Razão acena igualmente para um rompimento contextual: o Antropoceno, em suas complexidades, hierarquias e instabilidades, demanda ser compreendido enquanto evento ${ }^{104}$ histórico capaz de oportunizar a abertura contextual na medida em que o evento ascende em oposição à normalidade das aplicações rotineiras do direito, dos condicionamentos históricos evidentes - porém negli-

(Tradução nossa)

102 HAMILTON, Clive. Human destiny in the Anthropocene. In: HAMILTON, Clive; BONNEUIL, Christophe; GEMENNE, François (Eds.). The anthropocene and the global environmental crisis: rethinking modernity in a new epoch. New York: Routledge, 2015. p. 39. (Tradução nossa)

103 CHAKRABARTY, Dipesh. Postcolonial studies and the challenge of climate change. New Literary History, Baltimore, v. 43, n. 1, 2012. p. 15. (Tradução nossa)

104 A recente literatura que discute as conexões da categoria filosófica evento com o Direito Internacional pode ser explorada a partir de JOHNS, Fleur; JOYCE, Richard; PAHUJA, Sundhya. Introduction. In: JOHNS, Fleur; JOYCE, Richard; PAHUJA, Sundhya (Eds.). Events: the force of international law. London: Routledge, 2011. p. $1-17$ 
genciados -, assim produzindo a desconexão capaz de expandir o horizonte de expectativas. Este é um caminho para a inserção da esperada ampliação do espaço de experiências, uma ampliação contextual que nos mostra que "mesmo que hoje estejamos limitados pelos nossos contextos, nem tudo a respeito do nosso pensar e agir é determinado por eles." ${ }^{105}$

\section{Considerações finais}

Numa contribuição à abertura da tese do Antropoceno nas humanidades, o recurso à historiografia do Direito Internacional justifica-se vez que esse inovador campo de pesquisas busca incorporar o esforço de abertura e reconstrução do discurso histórico em diálogo com a pluralidade de atores e de narrativas. Igualmente, essa matriz teórica procede à problematização das relações entre presente e passado - porque desestabiliza os convencionais marcos historiográficos que respondem pela interpretação do passado-presente - e, finalmente, assimila posturas críticas em face de um propagado futuro comum da espécie humana.

A interpelação do Antropoceno em sua estrutura discursiva mostra-se relevante para a agenda internacionalista. Para tanto, deve ser destacada a recente problematização que Simon Lewis e Mark Aslim ${ }^{106}$ cuidadosamente empregaram na discussão de outros possíveis marcos temporais - eventos - aptos a desafiar a hegemonia da datação na Revolução Industrial. Viu-se que as objeções da historiografia pós-colonial empregadas no exame de normas e institutos jurídicos poderão contribuir para a compreensão das complexidades históricas do Antropoceno. O substancial mérito desse procedimento decorre da sobreposição, de um lado, de hipóteses geológicas voltadas para a apuração das atividades antropogênicas numa dimensão histórica conectada com a história da sociedade internacional e, de outro, dos condicionamentos ideológicos e da estrutura discursiva resultantes da adoção de alternativas à narrativa corrente da crise climática.

É, sobretudo, na crítica à história do Direito que foi abordada a complexidade do Antropoceno desde suas

105 KOSKENNIEMI, Martti. Victoria and us: thoughts on critical histories of international law. Zeitschrift des Max-Planck-Instituts für europäische Rechtsgeschichte, v. 22, p. 119-138, 2014. p. 135. (Tradução nossa) 106 LEWIS, Simon; MASLIN, Mark. Defining the anthropocene. Nature, Londres, v. 519, p. 171-180, 2015. estruturas hierárquicas internas até suas projeções de um futuro comum para a espécie. Se o Antropoceno também diz respeito a um passado colonial, e se esse passado é vivido em um espaço de experiência ampliado pelas injustiças de outros e outras, cumpre então indagar sobre as condições/coordenadas epistêmicas que desenham o horizonte de expectativas das discussões dominantes no contexto do colapso climático antropogênico. $\mathrm{Na}$ clivagem história humana vs história natural, a última pode estar se sobrepondo de modo irreversível sobre a primeira, e o que está ameaçada aparenta ser a realização das teleologias históricas a despontarem no Direito Internacional.

A título de desfecho deste trabalho, considere-se o panorama teórico que se apresenta à sociedade internacional no contexto do Antropoceno. Ao situar-se o direito em termos de linguagem normativa de dimensões históricas recorrentes, verifica-se que o mesmo guarda as coordenadas para a construção conjunta da vida em comunidade. Todavia, pode-se igualmente afirmar que o direito que rege determinada comunidade, em determinado marco geográfico e temporal - em nosso caso, o Direito Internacional do começo do século XXI -, paradoxalmente reúne os elementos considerados controversos vindos de passados que ainda repercutem nas normas e institutos jurídicos.

Novas formas de injustiças despontam em sincronia com o reconhecimento de que as assimetrias globais, usualmente mais visíveis na esfera econômica ou na distribuição de recursos, responderão por hierarquias discursivas que dizem respeito à atividade antropogênica historicamente considerada. Esta, desigual por excelência, impacta a todos, mas a muitos de forma mais severa e imediata. A capacidade do direito em formular problemas e soluções que atendam a tais novas demandas, no limite das possibilidades impostas - como, por exemplo, os Estados em vias de desaparecimento em razão do aumento do nível dos mares -, pode estar relacionada à sua capacidade para imaginar futuros possíveis nos quais Matafele Peinam, futura ex-nacional das Ilhas Marshall, possa realizar seus projetos de vida sem que, para isso, tenha de embarcar em uma jornada interestelar como os tripulantes de Aurora. Nesse momento, Gaia nos expulsará.

A história do direito desempenha um papel fundamental ao iluminar caminhos alternativos à regulação posta, ao identificar dimensões de injustiças históricas 
invisíveis às delimitações contextuais e ao desenhar um quadro mais completo para a tomada de decisões da vida em comunidade. Em contrapartida, o Antropoceno demanda dos historiadores a capacidade de refletir sobre extratos temporais de vastas escalas, sobre narrativas contraditórias de projetos universais, mas sempre contemplando o passado que, ao repercutir no presente, coloca o futuro em suspensão. Em contextos cada vez mais imprevisíveis, uma condicionalidade essencial revela-se no horizonte de expectativas da sociedade internacional: a história humana sofre intrusões daquela mesma Gaia que já foi considerada dominada. Paradoxalmente, será Gaia que inviabilizará a era da espécie bumana.

\section{REFERÊNCIAS BIBLIOGRÁFICAS}

AFONSO, Henrique Weil. A reconstrução histórica da diversidade no direito internacional. Rio de Janeiro: Lumen Juris, 2015.

AL ATTAR, Mohsen; MILLER, Rosalie. Towards an emancipatory international law: the bolivarian reconstruction. Third World Quarterly, Abingdon, v. 31, n. 3, p. 347-363, 2010.

ANGHIE, Antony. Imperialism, sovereignty and the making of international law. Cambridge: Cambridge University Press, 2004.

ALLEN, Myles et al. Climate change 2014 synthesis report. Approved summary for policymakers. International governmental synthesis report. Fifth assessment synthesis report. 2014. Disponível em: < http://www.ipcc.ch/report/ar5/wg2/>. Acesso em: 03 dez. 2015.

BANCO MUNDIAL. The 2016 edition of World Development Indicators is out. three features you don't want to miss. Disponível em: <http://blogs.worldbank.org/ opendata/2016-edition-world-development-indicatorsout-three-features-you-won-t-want-miss $>$. Acesso em: 18 maio 2016.

BARROS-PLATIAU, Ana Flávia et al. Correndo para o mar no antropoceno: a complexidade da governança dos oceanos e a estratégia brasileira de gestão dos recursos marinhos. Revista de Direito Internacional, Brasília, v. 12, n. 1, p. 149-168, 2015.

BONNEUIL, Christophe. The geological turn: narratives of the Anthropocene. In: HAMILTON, Clive; BONNEUIL, Christophe; GEMENNE, François (Eds.). The anthropocene and the global environmental cri- sis: rethinking modernity in a new epoch. New York: Routledge, 2015. p. 17-31.

CHAKRABARTY, Dipesh. Postcolonial studies and the challenge of climate change. New Literary History, Baltimore, v. 43, n.1, p. 1-18, 2012.

CHAKRABARTY, Dipesh. The climate of history: four theses. Critical Inquiry, Chicago, v. 35, n. 2, p. $197-$ 222, 2009.

COLLINGWOOD, Robin George. A história como representação da experiência passada. In: GARDINER, Patrick. Teorias da história. 4. ed. Lisboa: Fundação Calouste Gulbenkian, 1995.

CRUTZEN, Paul; STEFFEN, Will; MCNEILL, John. The anthropocene: are humans now overwhelming the great forces of nature? Ambio, Estocolmo, v. 36, n. 8, p. 614-621, 2007.

CRUTZEN, Paul; STOERMER, Eugene. The "Anthropocene”. Global Change Nensletter (IGBP), n. 41, p. 17-18, 2000.

DELOUGHREY, Elizabeth; HANDLEY, George. Introduction: Toward an Aesthetics of the Earth. In: DELOUGHREY, Elizabeth; HANDLEY, George (Eds.). Postcolonial ecologies: literatures of the environment. Oxford: Oxford University Press, 2011. p. 3-39.

DUSSEL, Enrique. 1492: o encobrimento do outro: a origem do mito da modernidade. Petrópolis: Vozes, 1993.

FALK, Richard. International law and the future. In: FALK, Richard; RAJAGOPAL, Balakrishnan; STEVENS, Jacqueline (Eds.). International law and the third world: reshaping justice. London: Routledge-Cavendish, 2008. p. 23-34.

FASOLT, Constantin. The limits of history. Chicago: University of Chicago Press, 2004.

FRANCO, Fernanda Cristina de Oliveira. Oportunidades e desafios das TWAIL no contex to latino-americano a partir das perspectivas dos povos indígenas ao direito internacional. Revista de Direito Internacional, Brasília, v. 12, n. 2, p. 226-244, 2015.

GALINDO, George Rodrigo Bandeira. Para que serve a história do direito internacional? Revista de Direito Internacional, Brasília, v. 12, n. 1, p. 339-354, 2015.

GATHII, James Thou. International law and eurocentricity. European Journal of International Law, Florença, v. 9, n. 1, p. 184-211, 1998. 
GREAR, Anna. Deconstructing Anthropos: a critical reflection on 'anthropocentric' law and anthropocene 'humanity". Law and Critique, Dordrecht, v. 26, n. 3, p. 225-249, 2015.

GREAR, Anna. Editorial. The discourse of 'biocultural' rights and the search of new epistemic parameters: moving beyond essentialisms and old certainties in an age of Anthropocene complexity? Journal of Human Rights and the Environment, v. 6, n. 1, p. 1-6, 2015.

GREGORY, Derek. The colonial present. Oxford: Blackwell Publishing, 2004.

GROSS, Leo. The peace of westphalia, 1648-1948. American Journal of International Law, Washington, v. 42, n. 1, p. 21-40, 1948.

GROVOGUI, Siba N'Zatioula. Sovereigns, quase sovereigns, and africans. Minneapolis: Minnesota University Press, 1996.

HAMILTON, Clive. Human destiny in the Anthropocene. In: HAMILTON, Clive; BONNEUIL, Christophe; GEMENNE, François (Eds.). The anthropocene and the global environmental crisis: rethinking modernity in a new epoch. New York: Routledge, 2015. p. 32-43.

HAMILTON, Clive; BONNEUIL, Christophe; GEMENNE, François. Thinking the Anthropocene. In: HAMILTON, Clive; BONNEUIL, Christophe; GEMENNE, Françoi. The anthropocene and the global environmental crisis: rethinking modernity in a new epoch. New York: Routledge, 2015. p. 1-13.

HERDER, Johann Gottfried. Ideias para a filosofia da história da humanidade. In: GARDINER, Patrick. Teorias da história. 4. ed. Lisboa: Fundação Calouste Gulbenkian, 1995.

HUNTER, Ian. Global justice and regional metaphisics: on the critical history of the law of nature and nations. In: DORSET'T, Shaunnagh; HUNTER, Ian (Eds.). Law and politics in british colonial thought. transpositions of empire. New York: Palgrave Macmillan, 2010. p. 11-30.

INTERNATIONAL LAW ASSOCIATION. Final report of the international committee on baselines under the international law of the sea. 75th Conference. Sofia, 2012. Disponível em: <www. ila-hq.org/en/committees/ index. cfm/cid/1028>. Acesso em: 25 maio 2016.

INTERGOVERNMENTAL PANEL ON CLIMATE CHANGE. IPCC Overview. 1990. Disponível em: $<$ http://www.ipcc.ch/publications_and_data/publica- tions_and_data_reports.shtml\#1>. Acesso em: 03 dez. 2015.

JAY, Martin. Historical explanation and the event: reflection on the limits of contextualization. New Literary History, Baltimore, v. 42, n. 4, p. 557-571, 2011.

JETNIL-KIJINER, Kathy. Dear metafele peinam. 2014. Disponível em: <https://jkijiner.wordpress. com/2014/09/24/united-nations-climate-summitopening-ceremony-my-poem-to-my-daughter/> . Acesso em: 10 jan. 2016.

JOHNS, Fleur; JOYCE, Richard; PAHUJA, Sundhya. Introduction. In: JOHNS, Fleur; JOYCE, Richard; PAHUJA, Sundhya (Eds.). Events: the force of international law. London: Routledge, 2011. p. 1-17.

KALMO, Hent; SKINNER, Quentin. Introduction: a concept in fragments. In: KALMO, Hent; SKINNER, Quentin (Eds.). Sovereignty in fragments: the past, present and future of a contested concept. Cambridge: Cambridge University Press, 2010. p. 1-25.

KIRSCH, Heitor Marcos; FILIPPI, Eduardo Ernesto. A dimensão ambiental do desenvolvimento: implicações para além do seu gerenciamento técnico-administrativo em um contexto de mudança climática. Revista de Direito Internacional, Brasília, v. 9, n. 3, p. 29-44, 2012.

KOSELLECK, Reinhart. Futuro passado: contribuição à semântica dos tempos modernos. Rio de Janeiro: Contraponto, 2012.

KOSKENNIEMI, Martti. Victoria and us: thoughts on critical histories of international law. Zeitschrift des MaxPlanck-Instituts für europäische Rechtsgeschichte, v. 22, p. 119138, 2014.

KOSKENNIEMI, Martti. Histories of international law: significance and problems for a critical view. Temple International and Comparative Law Journal, Philadelphia, v. 27, n. 2, p. 215-240, 2013.

KOSKENNIEMI, Martti. Law, teleology and international relations: an essay in counterdisciplinarity. International Relations, Aberystwyth, v. 26, n. 3, p. 3-34, 2012.

KOSKENNIEMI, Martti. Histories of international law: dealing with eurocentrism. Zeitschrift des MaxPlanck-Instituts für europäische Rechtsgeschichte, v. 19, p. 152176, 2011.

KOSKENNIEMI, Martti. The gentle civilizer of nations: the rise and fall of international law 1870-1960. Cam- 
bridge: Cambridge University Press, 2001.

LATOUR, Bruno. Telling friends from foes in the time of the Anthropocene. In: HAMILTON, Clive; BONNEUIL, Christophe; GEMENNE, François (Eds.). The anthropocene and the global environmental crisis: rethinking modernity in a new epoch. New York: Routledge, 2015. p. $145-155$.

LEWIS, Simon; MASLIN, Mark. Defining the Anthropocene. Nature, Londres, v. 519, p. 171-180, 2015.

MACEDO, Paulo Emílio Vauthier Borges de. O mito de Francisco de Vitória: defensor dos índios ou patriota espanhol? Revista de Direito Internacional, Brasília, v. 9, n. 1, p. 1-13, 2012.

MALM, Andreas; HORNBORG, Alf. The geology of mankind? a critique of the anthropocene narrative. The Anthropocene Review, v. 1, n. 1, p. 62-69, 2014.

MARQUES, Clarissa. When the future becomes the present of the environmental crisis: the jurisprudence of the Brazilian supreme court and the future dimension of the right to the environment. Revista de Direito da Cidade, Rio de Janeiro, v. 8, n. 2, p. 704-728, 2016.

MUTUA, Makau. What is TWAIL? proceedings of the 94th annual meeting of the american society of international law. 2000. Disponível em: < http://papers.ssrn. $\mathrm{com} / \mathrm{sol} 3 /$ papers.cfm?abstract-id $=1533471>$. Acesso em: 05 abr. 2012.

OAKLEY, Francis. Politics and eternity: studies in the history of medieval and early-modern political thought. Brill: Leiden, 1999.

OKAFOR, Obiora Chinedu. Newness, imperialism and international legal reform in Our time: a TWAIL perspective. Osgoode Hall Law Journal, Toronto, v. 43, n. 1, p. 171-191, 2005.

OPPENHEIM, Lassa. The science of international law: its task and method. American Journal of International Law, Washington, v. 2, n. 2, p. 313-356, 1908.

ORESKES, Naomi. The scientific consensus on climate change: how do we know we're not wrong? In: DIMENTO, Joseph F. C.; DOUGHMAN, Pamela (Eds). Climate change: what it means for us, our children, and our grandchildren. Cambridge: The MIT Press, 2007. p. $65-100$.

ORFORD, Anne. The past as law or history? the relevance of imperialism for modern international law. IILJ Wor- king Paper 2012. Disponível em: < http://www.iilj.org/ publications/documents/IILJ20122OrfordFINALrevisedtoreflectupdatededitors.pdf $>$. Acesso em: 30 nov. 2014.

OSOFSKY, Hari M. A right to frozen water? the institutional spaces for supranational climate change petitions. In: MILLER, Russell A.; BRATSPIES, Rebecca M. (Eds.). Progress in international law. Leiden: Martinus Nujhoff Publishers, 2008. p. 749-770.

PLUMWOOD, Val. Decolonizing relations with nature. In: ADAMS, William; MULLIGAN, Martin (Eds.). Decolonizing nature: strategies for conservation in a postcolonial era. London: Earthscan Publications, 2003. p. 51-78.

RAJAGOPAL, Balakrishnan. International law from below: development, social movements and third world resistance. Cambridge: Cambridge University Press, 2003.

ROBERTS, J. Timmons; PARKS, Bradley C. A climate of injustice: global inequality, north-south politics, and climate policy. Cambridge: The MIT Press, 2007.

SKINNER, Quentin. Meaning and Understanding in the History of Ideas. History and Theory, Middletown, v. 8, n. 1, p. 3-53, 1969.

STENGERS, Isabelle. No tempo das catástrofes: resistir à barbárie que se aproxima. São Paulo: Cosac Naify, 2015.

STENGERS, Isabelle. Accepting the reality of Gaia: a fundamental shift? In: HAMILTON, Clive; BONNEUIL, Christophe; GEMENNE, François (Eds.). The anthropocene and the global environmental crisis: rethinking modernity in a new epoch. New York: Routledge, 2015. p. 134-144.

TRÜPER, Henning; CHAKRABARTY, Dipesh; SUBRAHMANYAM, Sanjay. Introduction: Teleology and history: nineteenth-century fortunes of an enlightenment project. In: TRÜPER, Henning; CHAKRABARTY, Dipesh; SUBRAHMANYAM, Sanjay (Eds.). Historical teleologies in the modern world. Londres: Bloomsbury, 2015. p. 3-24

VIDAS, Davor. Sea-level rise and international law: at the convergence of two epochs. Climate Law, Leiden, v. 4, n. 1, p. 70-84, 2014.

VIDAS, Davor; ZALASIEWICZ, Jan; WILLIAMS, Mark. What is the Anthropocene: and Why is it relevant for International Law? Yearbook of International Environmental Law, Oxford, v. 25, n. 1, p. 3-23, 2015. 


\section{Agradecimento}

$\mathrm{O}$ autor gostaria de agradecer o auxílio financeiro da Coordenação de Aperfeiçoamento de Pessoal de Nível Superior que viabilizou a realização de Pós-Doutoramento junto ao Programa de Pós-Graduação em Direito Agroambiental da Universidade Federal de Mato Grosso no período 2014-2015. O presente trabalho apresenta as conclusões do referido estágio de pesquisa. 
Para publicar na Revista de Direito Internacional, acesse o endereço eletrônico www.rdi.uniceub.br ou www.brazilianjournal.org.

Observe as normas de publicação, para facilitar e agilizar o trabalho de edição. 